HETEROCYCLES, Vol. 87, No. 11, 2013, pp.-. (C) The Japan Institute of Heterocyclic Chemistry

Received, 3rd September, 2013, Accepted, 25th September, 2013, Published online,

DOI: $10.3987 / \mathrm{COM}-13-12827$

\title{
SYNTHESIS AND IN VITRO ANTITUMOR EFFECT OF NEW VINDOLINE DERIVATIVES COUPLED WITH AMINO ACID ESTERS
}

\author{
Péter Keglevich, ${ }^{a}$ László Hazai, ${ }^{a}$ Álmos Gorka-Kereskényi, ${ }^{a}$ Lilla Péter, \\ Judit Gyenese, ${ }^{a}$ Zsófia Lengyel, ${ }^{a}$ György Kalaus, ${ }^{a}$ Zsófia Dubrovay, ${ }^{b}$ Miklós \\ Dékány, ${ }^{\mathrm{b}}$ Erika Orbán, ${ }^{\mathrm{c}}$ Ildikó Szabó, ${ }^{\mathrm{c}}$ Zoltán Bánóczi, ${ }^{\mathrm{c}}$ Csaba Szántay, Jr., \\ and Csaba Szántay ${ }^{\mathrm{a}^{*}}$
}

\author{
${ }^{a}$ Department of Organic Chemistry and Technology, University of Technology \\ and Economics, Gellért tér 4, H-1111 Budapest, Hungary, 'bpectroscopic \\ Research Division, Gedeon Richter Plc., P. O. Box 27, H-1475 Budapest 10, \\ Hungary, 'Research Group of Peptide Chemistry, Eötvös L. University, \\ Hungarian Academy of Sciences, P. O. Box 32, H-1518 Budapest 112, Hungary; \\ E-mail: szantay@mail.bme.hu
}

\begin{abstract}
Bromovindoline and its 14,15-dihydro- and 14,15-cyclopropano derivatives were coupled in the position 16 with (L)- and (D)-tryptophan methyl esters. The tryptophan derivatives of vindoline were synthesized starting from the 16-carboxylic acid hydrazides via the corresponding azides which were allowed to react with the amino acid esters. The new compounds showed antitumor activity against human leukemia (HL-60) cells in vitro.
\end{abstract}

\section{INTRODUCTION}

The Vinca alkaloids vinblastine (1) and vincristine (2) have been widely used in antitumor therapy for about 50 years. These dimeric alkaloids have two monomer alkaloid parts: vindoline (3) and catharanthine (4) (Scheme 1). The chemistry and pharmacology of vinblastine and vincristine are well known, and a number of their derivatives were synthesized to improve their therapeutic properties. ${ }^{1}$ However, vindoline and its derivatives were found to be biologically insignificant, therefore there is much fewer data on their chemistry and biological effect in the literature. ${ }^{2}$ 


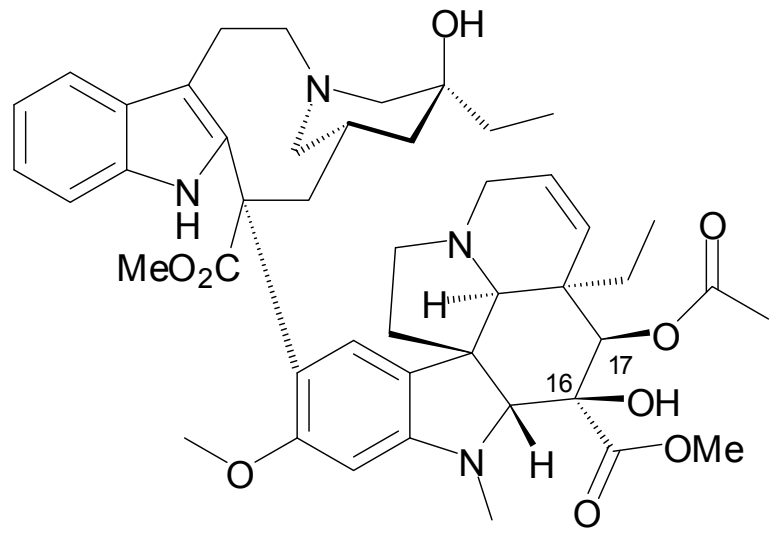

1

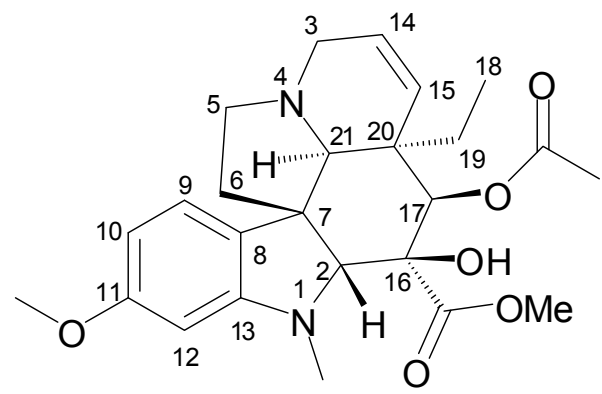

3
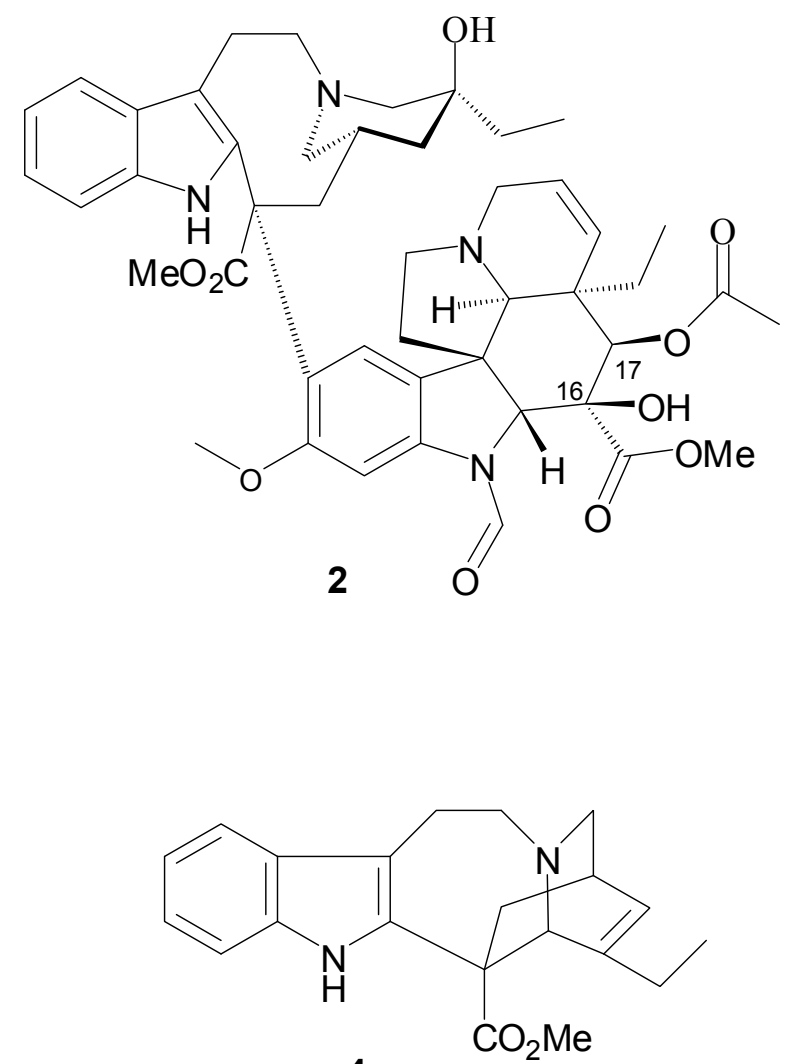

4

\section{Scheme 1}

Our research project was conceived on the basis of two interesting experiences in connection with dimeric alkaloids.

Firstly, some amino acid derivatives of vinblastine and vincristine were synthesized by coupling amino acid esters with the vindoline part in position $16 .^{3}$ The obtained conjugates exhibited significant antitumor effect against P388 and L1210 leukemia in mice. At the same time (D)- and (L)-tryptophan derivatives at the 16-position of desacetylvinblastine were conjugated through the carboxyl group with oligoarginine octapeptide as a carrier peptide at the $\mathrm{N}$-terminus by Bánóczi et $a l{ }^{4}$ One of the obtained stereoisomers showed a selective cytotoxic effect against the HL-60 human leukemia cells of higher proliferation rate. Secondly, for dihydrovinblastine (i.e. vinblastine saturated in the 14,15-position of the vindoline part) a decreased antitumor activity and toxicity was observed, probably due to a different mechanism of action from vinblastine. ${ }^{5}$

These observations suggest that amino acid conjugation and reduction of the 14,15-position both alter the mechanism of action. Based on these observations our goal was to couple vindoline (3), 14,15-dihydrovindoline (6), and vindoline condensed with a cyclopropane ring in position 14,15, with 
(L)- and (D)-tryptophan methyl ester, as in the case of desacetylvinblastine, ${ }^{4}$ at position 16 with a view to screening their biological effect. The azide coupling method known from peptide chemistry was used as the key step in the coupling of vindoline with the amino group of the amino acid ester.

\section{RESULTS AND DISCUSSION}

\section{Chemistry}

The first task was to protect position 10 of vindoline, because in the presence of sodium nitrite used in the preparation of the corresponding azide, a nitrosation reaction took place in position 10, resulting in 10-nitrosovindoline. ${ }^{2}$ In this procedure a bromo substituent was used to protect position 10 (Scheme 2).
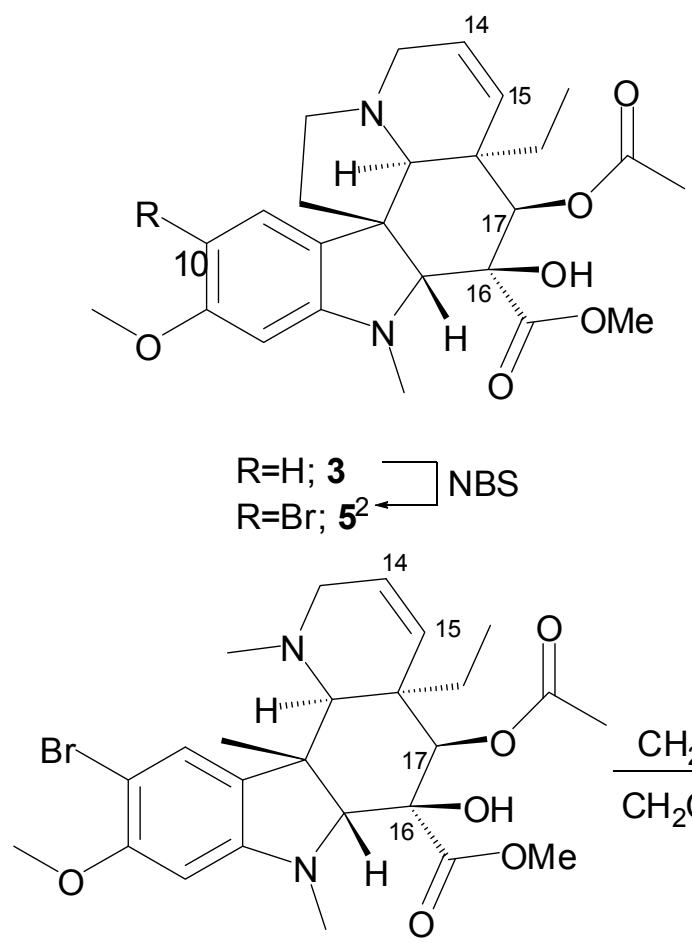

5

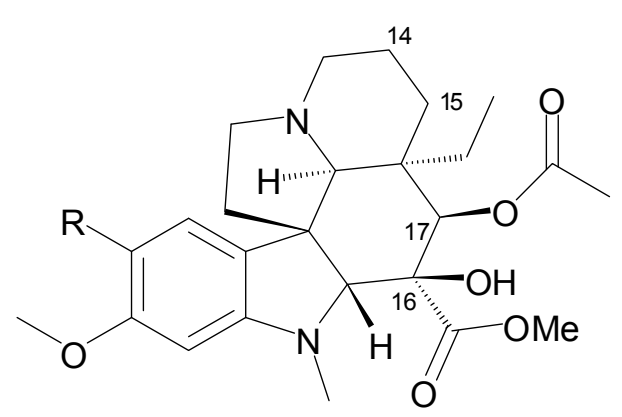

$\mathrm{R}=\mathrm{H} ; \mathbf{6}^{6}$
$\mathrm{R}=\mathrm{Br} ; \mathbf{7}(90 \%) \longleftarrow \mathrm{NBS}$

8

\section{Scheme 2}

10-Bromovindoline (5) was prepared by us from vindoline (3) in a simple bromination reaction using $N$-bromosuccinimide. $^{2} 14,15$-Dihydrovindoline (6) is known from the literature, ${ }^{6}$ and was obtained by catalytic hydrogenation of vindoline (3). Analogously with the previous reaction, bromination of the saturated derivative 6 resulted in 10-bromo-14,15-dihydrovindoline (7). The cyclopropane ring was built into position 14,15 by a typical Simmons-Smith reaction from 10-bromovindoline (5) using diethylzinc and diiodomethane, yielding compound $\mathbf{8}$. 


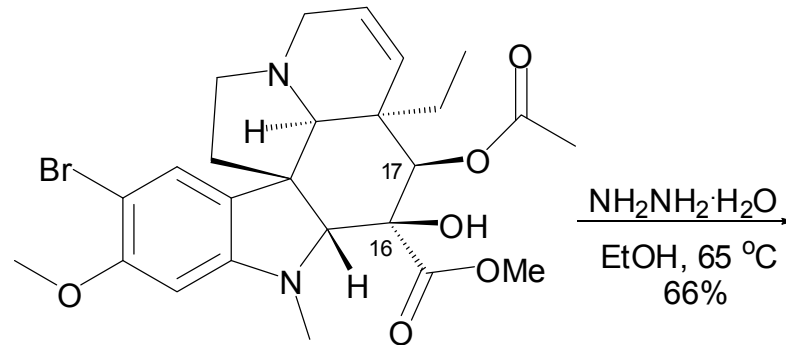

5

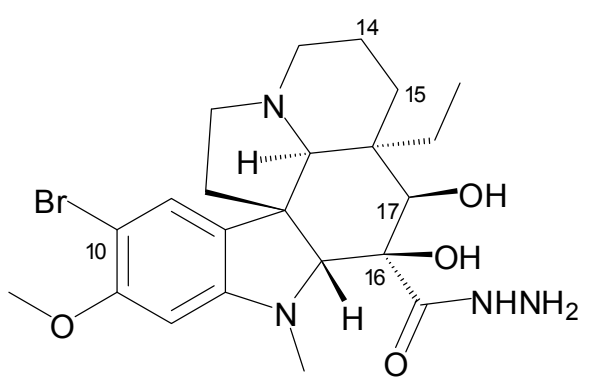

9b $(39 \%)$

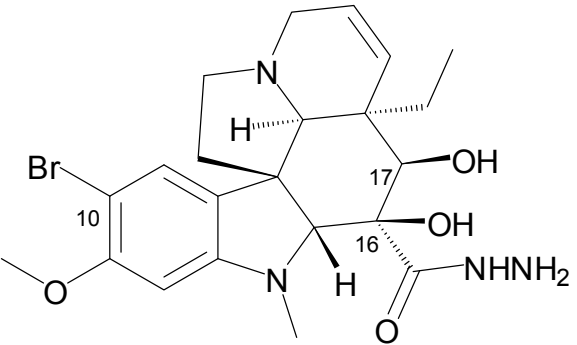

$9 a$

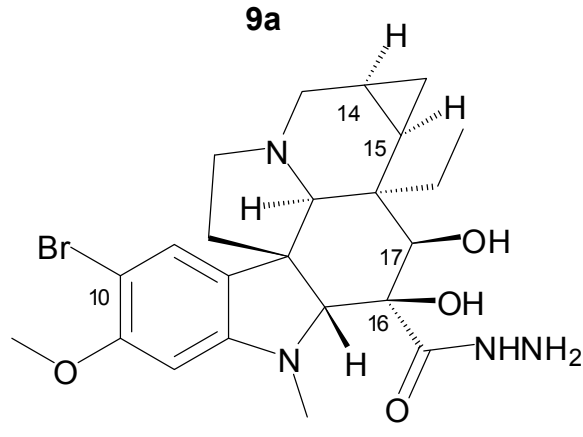

9c $(55 \%)$

\section{Scheme 3}

Hydrazides of 10-bromovindoline (9a), 14,15-dihydrovindoline (9b), and 14,15-cyclopropanovindoline (9c), were synthesized from the corresponding bromo esters 10-bromovindoline

10-bromo-14,15-dihydrovindoline (7), and 10-bromo-14,15-cyclopropanovindoline (8), respectively, with hydrazine hydrate (Scheme 3). Hydrazine, as a strong nucleophile, caused desacetylation in position 17 during the reaction, and so the 17-desacetylated hydrazides were obtained as products.

Coupling the vindoline derivatives with tryptophan methyl esters was achieved by preparation of the azides (Scheme 4). The reaction of hydrazide 9a with sodium nitrite in methanol in the presence of hydrochloric acid resulted in azide 10a, which was then allowed to react without isolation with (L)-tryptophan methyl ester to yield the vindoline conjugate $\mathbf{1 1 a}$.

Using this procedure 14,15-dihydrovindoline and 14,15-cyclopropanovindoline were also coupled with (L)-tryptophan methyl ester, yielding compounds 11e and 11i, respectively. The derivatives containing (D)-tryptophan methyl ester (11c, 11g, 11k) were synthesized analogously.

In the case of compounds 11a, 11c, 11e, 11g, 11i and 11k, the bromo substituent was removed from position 10 by hydrogenolysis to give compounds $\mathbf{1 1 b}, \mathbf{1 1 d}, \mathbf{1 1 f}, \mathbf{1 1 h}, \mathbf{1 1 j}$ and $\mathbf{1 1 l}$, respectively. 


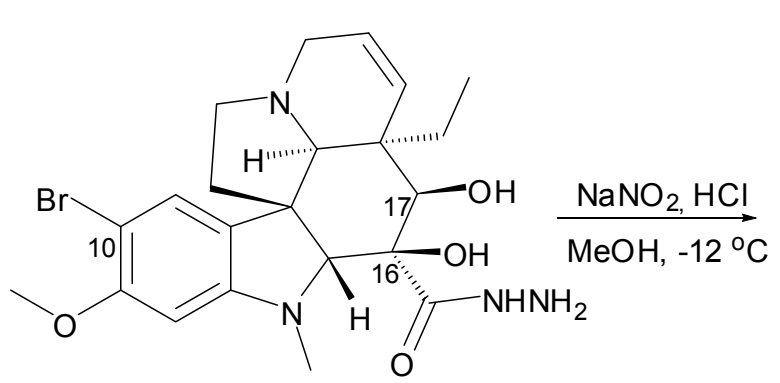

$9 a$
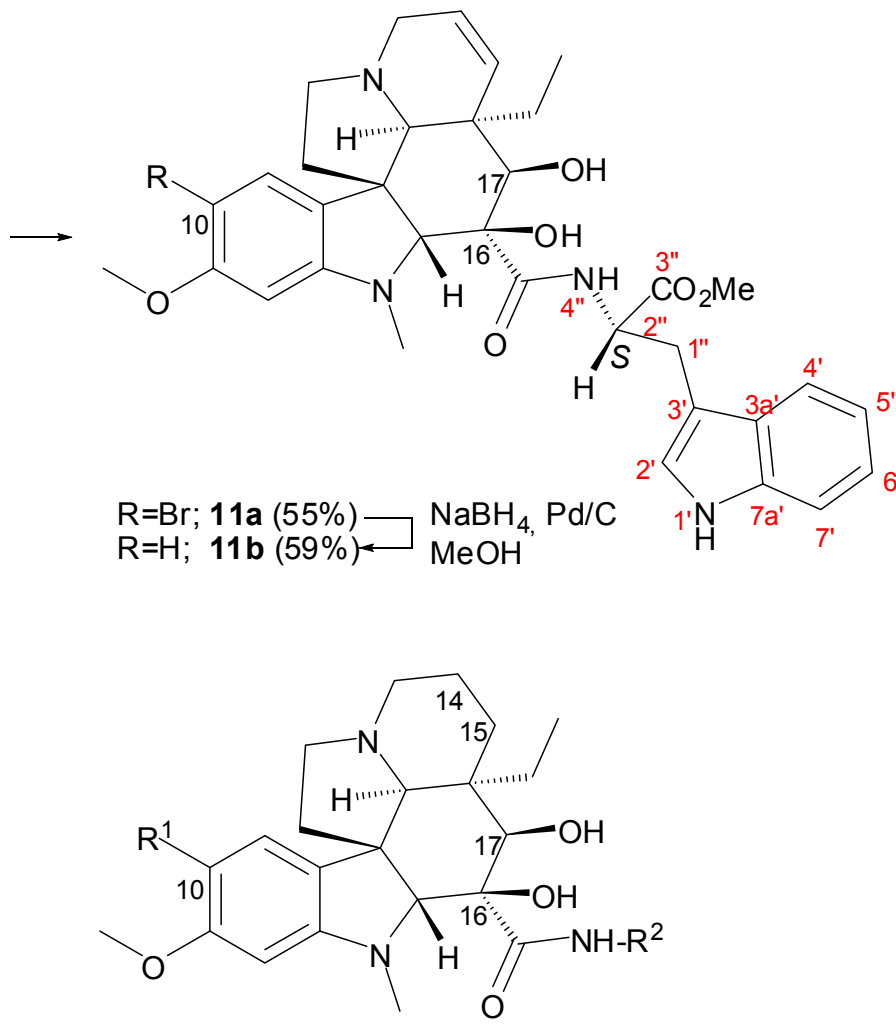

$\mathrm{R}^{1}=\mathrm{Br} ; \mathrm{R}^{2}=-(S)-\operatorname{Trp}-\mathrm{OMe} 11 \mathrm{e}(33 \%) \longrightarrow \mathrm{NaBH}_{4}, \mathrm{Pd} / \mathrm{C}$

$\mathrm{R}^{1}=\mathrm{H} ; \mathrm{R}^{2}=-(S)-\operatorname{Trp}-O M e 11 f(51 \%) \longleftarrow \mathrm{MeOH}$

$\mathrm{R}^{1}=\mathrm{Br} ; \mathrm{R}^{2}=-(R)-\operatorname{Trp}-\mathrm{OMe} 11 \mathrm{~g}(34 \%) \longrightarrow \mathrm{NaBH}_{4}, \mathrm{Pd} / \mathrm{C}$

$\mathrm{R}^{1}=\mathrm{H} ; \mathrm{R}^{2}=-(R)-\operatorname{Trp}-\mathrm{OMe} 11 \mathrm{~h}(46 \%) \longleftarrow \mathrm{MeOH}$

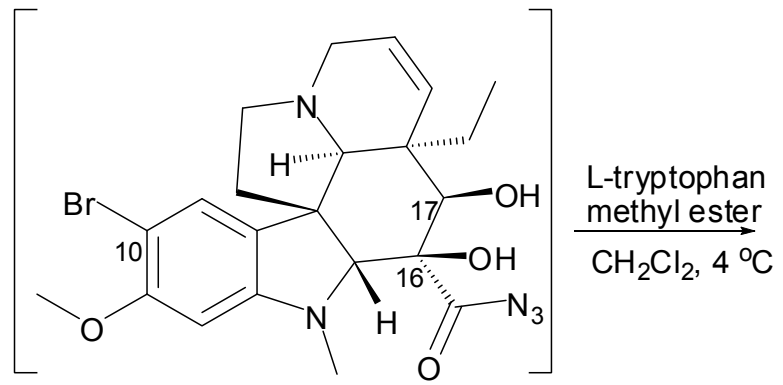

$10 a$

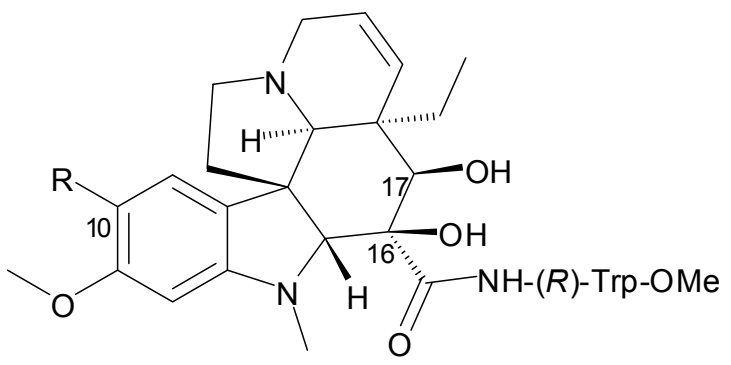

$\mathrm{R}=\mathrm{Br} ; 11 \mathrm{c}(26 \%) \longrightarrow \mathrm{NaBH}_{4}, \mathrm{Pd} / \mathrm{C}$ $\mathrm{R}=\mathrm{H} ; 11 \mathrm{~d}(70 \%) \longleftarrow \mathrm{MeOH}$

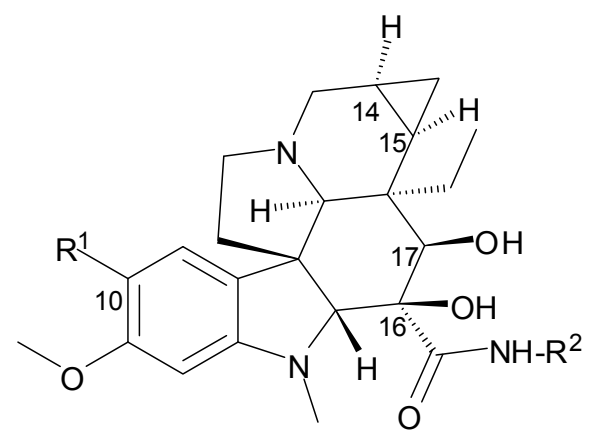

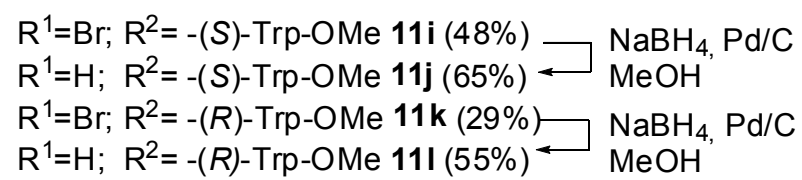

\section{Scheme 4}

\section{Biology}

The influence of the different modifications of the ring system and/or the conjugation with tryptophan on the in vitro cytostasis of HL-60 human leukemia cells was analysed by using MTT assay (Table 1). Vindoline, as expected (2), exhibited no effect in the concentration range applied $\left(2.6 \times 10^{-4}-10^{2} \mu \mathrm{M}\right)$. Compound 11 showed the highest activity $\left.\mathrm{IC}_{50}=27.5 \pm 1.5\right)$. In this compound there is a saturated double bond (14,15-dihydro moiety), but no $\mathrm{Br}$ in position 10 . The appearance of $\mathrm{Br}$ at this position resulted in a significant (2-fold) drop in cytostatic activity $\left(\mathrm{IC}_{50}=60.1 \pm 15.0\right.$ for 11e vs. $27.5 \pm 1.5$ for 11f). The importance of the saturated bond between $\mathrm{C} 14$ and $\mathrm{C} 15$ could be emphasized also by the comparison of 
the compounds $\mathbf{1 1 b}$ and $\mathbf{1 1 f}$. Compound $11 \mathrm{f}$ with saturation was more effective then compound $\mathbf{1 1 b}$ with double bond $\left(\mathrm{IC}_{50}=27.5 \pm 1.5\right.$ for $\mathbf{1 1 f}$ vs $54.3 \pm 6.7$ for $\left.\mathbf{1 1 b}\right)$. The introduction of $\mathrm{Br}$ at position 10 into compound $\mathbf{1 1 b}$ resulted in essentially no change in the $\mathrm{IC}_{50}$ values $\left(\mathrm{IC}_{50}=54.3 \pm 6.7\right.$ for $\mathbf{1 1 b}$ vs. $56.8 \pm 9.8$ for 11a). However, the introduction of $14(S), 15(R)$-cyclopropano part into compound $\mathbf{1 1 b}$ decreased the activity of both non-brominated (11j) and brominated (11i) derivatives $\left(\mathrm{IC}_{50}=54.3 \pm 6.7\right.$ for $\mathbf{1 1 b}$ vs. $77.1 \pm 8.1$ for $\mathbf{1 1} \mathbf{j}$ or $75.3 \pm 2.3$ for $\mathbf{1 1 i})$. The comparison of cytostatic activity of pairs with L- or D-Trp methylester shows no markedly altered $\mathrm{IC}_{50}$ values in 10-bromo substituted and unsubtituted compounds $\left(\mathrm{IC}_{50}=56.8 \pm 9.8\right.$ for 11a vs $73.8 \pm 10.4$ for $11 \mathrm{c}$ and $\mathrm{IC}_{50}=54.3 \pm 6.7$ for $\mathbf{1 1 b}$ vs $73.0 \pm 2.3$ 11d $)$, 10-bromo substituted compounds with saturated bond between $\mathrm{C} 14$ and $\mathrm{C} 15\left(\mathrm{IC}_{50}=60.1 \pm 15.0\right.$ for 11e vs $60.8 \pm 1.3$ for 11g) or with added $14(S), 15(R)$-cyclopropano ring $\left(\mathrm{IC}_{50}=75.3 \pm 2.3\right.$ for 11i vs. $\mathrm{IC}_{50}=72.6 \pm 4.0$ for 11k). Interestingly, the $14(S), 15(R)$-cyclopropano derivative of $\mathrm{D}$-TrpOMe $\left(\mathrm{IC}_{50}>100\right.$ for 11l) was inactive, while the conjugate with L-TrpOMe $\left(\mathrm{IC}_{50}=77.1 \pm 8.1\right.$ for $\left.\mathbf{1 1} \mathbf{j}\right)$ had measurable in vitro cytostatic effect. Also was difference in the activity of the best compound with L-TrpOMe $\left(\mathrm{IC}_{50}=27.5 \pm 1.5\right.$ for 11f) and its D-TrpOMe derivative $\left(\mathrm{IC}_{50}=78.4 \pm 9.7\right.$ for $\left.\mathbf{1 1 h}\right)$.

Table 1. Cytostatic activity of vindoline derivatives on HL-60 cells

\begin{tabular}{|c|c|c|}
\hline Compound & Code & $\begin{array}{c}\mathrm{IC}_{50} \\
(\mu \mathrm{M}) \pm \text { s.d. }\end{array}$ \\
\hline $\begin{array}{l}\text { Methyl- }\{N \text {-[10-bromo-17-O-desacetyl-16-des(methoxycarbonyl)- } \\
\text { vindoline-16-carbonyl]-L-Trp }\}\end{array}$ & $11 \mathrm{a}$ & $56.8 \pm 9.8$ \\
\hline $\begin{array}{l}\text { Methyl- }\{N \text {-[10-bromo-17-O-desacetyl-16-des(methoxycarbonyl)- } \\
\text { vindoline-16-carbonyl]-D-Trp }\}\end{array}$ & 11c & $73.8 \pm 10.4$ \\
\hline $\begin{array}{l}\text { Methyl- }\{N \text {-[17-O-desacetyl-16-des(methoxycarbonyl)- } \\
\text { vindoline-16-carbonyl]-L-Trp }\}\end{array}$ & 11b & $54.3 \pm 6.7$ \\
\hline $\begin{array}{l}\text { Methyl- }\{N \text {-[17- } O \text {-desacetyl-16-des(methoxycarbonyl)- } \\
\text { vindoline-16-carbonyl]-D-Trp }\}\end{array}$ & 11d & $73.0 \pm 2.3$ \\
\hline $\begin{array}{l}\text { Methyl- }\{N \text {-[10-bromo-14,15-dihydro-17-O-desacetyl-16- } \\
\text { des(methoxycarbonyl)vindoline-16-carbonyl]-L-Trp }\}\end{array}$ & $11 \mathrm{e}$ & $60.1 \pm 15.0$ \\
\hline $\begin{array}{l}\text { Methyl- }\{N \text {-[14,15-dihydro-17-O-desacetyl-16-des(methoxycarbonyl)- } \\
\text { vindoline-16-carbonyl]-L-Trp }\}\end{array}$ & 11f & $27.5 \pm 1.5$ \\
\hline $\begin{array}{l}\text { Methyl- }\{N \text {-[10-bromo-14,15-dihydro-17-O-desacetyl-16- } \\
\text { des(methoxycarbonyl)vindoline-16-carbonyl]-D-Trp }\}\end{array}$ & $11 \mathrm{~g}$ & $60.8 \pm 1.3$ \\
\hline $\begin{array}{l}\text { Methyl- }\{N \text {-[14,15-dihydro-17-O-desacetyl-16-des(methoxycarbonyl)vindoline- } \\
\text { 16-carbonyl]-D-Trp }\}\end{array}$ & $11 \mathrm{~h}$ & $78.4 \pm 9.7$ \\
\hline $\begin{array}{l}\text { Methyl- }\{N \text {-[10-bromo-14(S),15(R)-cyclopropano-17-O-desacetyl- } \\
\text { 16-des(methoxycarbonyl)vindoline-16-carbonyl]-L-Trp }\}\end{array}$ & $11 \mathrm{i}$ & $75.3 \pm 2.3$ \\
\hline $\begin{array}{l}\text { Methyl- }\{N \text {-[10-bromo-14(S),15(R)-cyclopropano-17-O-desacetyl- } \\
\text { 16-des(methoxycarbonyl)vindoline-16-carbonyl]-D-Trp }\}\end{array}$ & $11 \mathrm{k}$ & $72.6 \pm 4.0$ \\
\hline
\end{tabular}




\begin{tabular}{lcc}
\hline $\begin{array}{l}\text { Methyl- }\{N-[14(S), 15(R) \text {-cyclopropano-17-O-desacetyl-16- } \\
\text { des(methoxycarbonyl)vindoline-16-carbonyl]-L-Trp }\}\end{array}$ & $\mathbf{1 1 j}$ & $\mathbf{7 7 . 1 \pm 8 . 1}$ \\
\hline $\begin{array}{l}\text { Methyl- }\{N-[14(S), 15(R) \text {-cyclopropano-17-O-desacetyl-16- } \\
\text { des(methoxycarbonyl)vindoline-16-carbonyl]-D-Trp }\}\end{array}$ & $\mathbf{1 1 l}$ & $>100$ \\
\hline Vindoline & $\mathbf{3}$ & $>100$ \\
& & \\
\hline
\end{tabular}

\section{EXPERIMENTAL}

\section{General}

Melting points are uncorrected. IR spectra were recorded on Zeiss IR 75 and 80 instruments. NMR measurements were performed on a Varian $800 \mathrm{MHz}$ NMR spectrometer equipped with a ${ }^{1} \mathrm{H}\left\{{ }^{13} \mathrm{C} /{ }^{15} \mathrm{~N}\right\}$ Triple Resonance ${ }^{13} \mathrm{C}$ Enhanced Salt Tolerant Cold Probe operating at $800 \mathrm{MHz}$ for ${ }^{1} \mathrm{H}$ and $201 \mathrm{MHz}$ for ${ }^{13} \mathrm{C}$, and a Varian $500 \mathrm{MHz}$ NMR spectrometer equipped with a ${ }^{1} \mathrm{H}\left\{{ }^{13} \mathrm{C} /{ }^{15} \mathrm{~N}\right\} 5 \mathrm{~mm}$ PFG Triple Resonance ${ }^{13} \mathrm{C}$ Enhanced Cold Probe operating at $500 \mathrm{MHz}$ for ${ }^{1} \mathrm{H}$ and $125 \mathrm{MHz}$ for ${ }^{13} \mathrm{C}$. Chemical shifts are given on the delta scale as parts per million (ppm) with tetramethylsilane (TMS) $\left({ }^{1} \mathrm{H}\right)$ or dimethylsulfoxide- $d_{6}\left({ }^{13} \mathrm{C}\right)$ as the internal standard (0.00 ppm and $39.5 \mathrm{ppm}$, respectively). ${ }^{1} \mathrm{H}-{ }^{1} \mathrm{H}$, direct ${ }^{1} \mathrm{H}-{ }^{13} \mathrm{C}$, and long-range ${ }^{1} \mathrm{H}-{ }^{13} \mathrm{C}$ scalar spin-spin connectivities were established from 2D gDQFCOSY, zTOCSY, gHSQCAD, and gHMBCAD experiments, respectively. All pulse sequences were applied by using the standard spectrometer software package. All experiments were performed at $298 \mathrm{~K}$. HRMS analyses were performed on an LTQ FT Ultra (Thermo Fisher Scientific, Bremen, Germany) system. The ionization method was ESI operated in positive ion mode. For the CID experiment helium was used as the collision gas, and normalized collision energy (expressed in percentage), which is a measure of the amplitude of the resonance excitation RF voltage applied to the endcaps of the linear ion trap, was used to induce fragmentation. The protonated molecular ion peaks were fragmented by CID at a normalized collision energy of 35-50\%. The samples were dissolved in methanol. Data acquisition and analysis were accomplished with Xcalibur software version 2.0 (Thermo Fisher Scientific). TLC was carried out using Kieselgel 60F 254 (Merck) glass plates.

10-Bromo-14,15-dihydrovindoline (7). Dihydrovindoline ${ }^{6}(6)(280 \mathrm{mg}, 0.61 \mathrm{mmol})$ was dissolved in $\mathrm{CH}_{2} \mathrm{Cl}_{2}(10 \mathrm{~mL})$ and $114 \mathrm{mg}(0.64 \mathrm{mmol})$ of $N$-bromosuccinimide was added. The reaction mixture was stirred for $45 \mathrm{~min}$. Then the solution was washed with $5 \%$ aq. sodium hydrogen carbonate $(10 \mathrm{~mL})$ and with water $(10 \mathrm{~mL})$. The organic layer was dried with magnesium sulfate and the solvent was evaporated in vacuum. $295 \mathrm{mg}(90 \%)$ of 7 was obtained, mp $229{ }^{\circ} \mathrm{C}$. TLC $\left(\mathrm{CH}_{2} \mathrm{Cl}_{2}-\mathrm{MeOH} 10: 1\right), R_{f}=0.80 .[\alpha]^{32}{ }_{\mathrm{D}}$ +6.5 (c 1, $\mathrm{CH}_{2} \mathrm{Cl}_{2}$ ). IR (KBr): 3439, 1738, 1462, 1244, 1043, 888, $812 \mathrm{~cm}^{-1} .{ }^{1} \mathrm{H}$ NMR $(500 \mathrm{MHz}$, DMSO- $\left.d_{6}\right) \delta 0.46\left(\mathrm{t}, J=7.5 \mathrm{~Hz}, 3 \mathrm{H}, \mathrm{H}_{3}-18\right) ; 0.93\left(\mathrm{ABq}, J=14.4, J=7.5 \mathrm{~Hz}, 1 \mathrm{H}, \mathrm{H}_{\mathrm{x}}-19\right) ; 1.15(\mathrm{td}, J=$ 
$\left.13.8, J=3.7 \mathrm{~Hz}, 1 \mathrm{H}, \mathrm{H}_{\mathrm{ax}}-15\right) ; 1.25\left(\mathrm{~d} \mathrm{br}, J=13.8 \mathrm{~Hz}, 1 \mathrm{H}, \mathrm{H}_{\mathrm{eq}}-15\right) ; 1.30(\mathrm{ABq}, J=14.4, J=7.5 \mathrm{~Hz}, 1 \mathrm{H}$, $\mathrm{H}_{\mathrm{y}}-19$ ); 1.56 (d br, $\left.J=12.8 \mathrm{~Hz}, 1 \mathrm{H}, \mathrm{H}_{\mathrm{eq}}-14\right) ; 1.73$ (qt, $\left.J=12.8, J=3.7 \mathrm{~Hz}, 1 \mathrm{H}, \mathrm{H}_{\mathrm{ax}}-14\right) ; 1.98$ (s, 3H, $\left.\mathrm{H}_{3}-\mathrm{C}(17) \mathrm{OCOCH}_{3}\right) ; 2.08$ (br, 1H, $\left.\mathrm{H}_{\alpha}-3\right) ; 2.15-2.23$ (m, 2H, $\left.\mathrm{H}_{2}-6\right) ; 2.27$ (br, $\left.1 \mathrm{H}, \mathrm{H}-21\right) ; 2.57$ (s, 3H, $\mathrm{H}_{3}-\mathrm{N}(1) \mathrm{CH}_{3}$ ); 2.59 (br, $\left.1 \mathrm{H}, \mathrm{H}_{\alpha}-5\right) ; 3.09$ (d br, $J=9.1 \mathrm{~Hz}, 1 \mathrm{H}, \mathrm{H}_{\beta}-3$ ); 3.16 (t br, $J=9.1 \mathrm{~Hz}, 1 \mathrm{H}, \mathrm{H}_{\beta}-5$ ); 3.57 (s, 1H, H-2); 3.69 (s, 3H, H3-C(16) $\left.\mathrm{COOCH}_{3}\right) ; 3.79$ (s, 3H, H3-C(11)OCH $)_{3}$; 5.37 (s, 1H, H-17); 6.43 $(\mathrm{s}, 1 \mathrm{H}, \mathrm{H}-12) ; 7.36$ (s, 1H, H-9); 9.32 (s, 1H, OH). ${ }^{13} \mathrm{C}-\mathrm{NMR}\left(125 \mathrm{MHz}, \mathrm{DMSO}-d_{6}\right) \delta 7.8(\mathrm{C}-18) ; 20.7$ $\left(\mathrm{C}-\mathrm{C}(17) \mathrm{OCOCH}_{3}\right) ; 22.2$ (C-14); 29.5 (C-15); 32.8 (C-19); 37.9 (C-1); 42.4 (C-20); 43.3 (C-6); 50.7 (C-3); $51.7(\mathrm{C}-5) ; 52.0\left(\mathrm{C}-\mathrm{C}(16) \mathrm{COOCH}_{3}\right) ; 52.0(\mathrm{C}-7) ; 56.3\left(\mathrm{C}-\mathrm{C}(11) \mathrm{OCH}_{3}\right) ; 71.5$ (C-21); $75.1(\mathrm{C}-17)$; 77.8 (C-16); 83.0 (C-2); 95.2 (C-12); 99.2 (C-10); 126.7 (C-9); 127.5 (C-8); 153.5 (C-13); 156.0 (C-11); $169.6\left(\mathrm{C}-\mathrm{C}(17) \mathrm{OCOCH}_{3}\right) ; 172.1 \quad\left(\mathrm{C}-\mathrm{C}(16) \underline{\mathrm{COOCH}_{3}}\right) . \quad$ HRMS: $537.15972 \quad\left(\mathrm{C}_{25} \mathrm{H}_{34} \mathrm{O}_{6} \mathrm{~N}_{2} \mathrm{Br} ; \quad\right.$ calc. 537.15948). ESI-MS-MS (rel. int. \%): 477(100); 445(5); 417(7); 266(11).

10-Bromo-14(S),15(R)-cyclopropanovindoline (8). 10-Bromovindoline ${ }^{2}$ (5) (1.466 g, $\left.2.74 \mathrm{mmol}\right)$ was dissolved in $\mathrm{CH}_{2} \mathrm{Cl}_{2}(50 \mathrm{~mL})$ under argon, and at $0{ }^{\circ} \mathrm{C}$ diethylzinc $(6.99 \mathrm{~mL}, 6.99 \mathrm{mmol})$ in $1 \mathrm{M}$ hexane solution, then $\mathrm{CH}_{2} \mathrm{Cl}_{2}(0.44 \mathrm{~mL}, 5.46 \mathrm{mmol})$ were injected into the solution. The reaction mixture was stirred for $30 \mathrm{~min}$ at $0{ }^{\circ} \mathrm{C}$ and then for $6 \mathrm{~h}$ at room temperature. After allowing to stand overnight, further diethylzinc $(6.99 \mathrm{~mL})$ and $\mathrm{CH}_{2} \mathrm{Cl}_{2}(0.44 \mathrm{~mL})$ were added. After stirring for $4 \mathrm{~h}$ at room temperature the reaction mixture was filtered, $\mathrm{CH}_{2} \mathrm{Cl}_{2}(100 \mathrm{~mL})$ was added to the filtrate and was washed with water $(100$ $\mathrm{mL})$. The aqueous phase was washed with $\mathrm{CH}_{2} \mathrm{Cl}_{2}(2 \times 50 \mathrm{~mL})$. The combined organic phase was dried with magnesium sulfate and the solvent was evaporated in vacuum. The crude product was purified by preparative TLC $\left(\mathrm{CH}_{2} \mathrm{Cl}_{2}-\mathrm{MeOH} 20: 1\right)$ and $910 \mathrm{mg}(60 \%)$ of 8 was isolated as a yellow solid, mp 226-228 ${ }^{\circ} \mathrm{C}$. TLC $\left(\mathrm{CH}_{2} \mathrm{Cl}_{2}-\mathrm{MeOH} 20: 1\right), R_{f}=0.50 .[\alpha]^{22} \mathrm{D}-50.9\left(c 1, \mathrm{CHCl}_{3}\right)$. IR (KBr): 3436, 2970, 1748, 1728, 1253, 1188, $960 \mathrm{~cm}^{-1} .{ }^{1} \mathrm{H}$ NMR (500 MHz, DMSO-d $)_{6} \delta 0.29\left(\mathrm{~m}, 1 \mathrm{H}, \mathrm{H}_{\alpha}-15\right) ; 0.60\left(\mathrm{~m}, 1 \mathrm{H}, \mathrm{H}_{\mathrm{x}}-22\right)$; 0.67 (t, $\left.J=7.5 \mathrm{~Hz}, 3 \mathrm{H}, \mathrm{H}_{3}-18\right) ; 0.78$ (ABq, $\left.J=14.1, J=7.0 \mathrm{~Hz}, 1 \mathrm{H}, \mathrm{H}_{\mathrm{x}}-19\right) ; 0.81\left(\mathrm{~m}, 1 \mathrm{H}, \mathrm{H}_{\mathrm{y}}-22\right) ; 1.14$ (m, 1H, $\left.\mathrm{H}_{\alpha^{-}}-14\right) ; 1.71$ (ABq, $\left.J=14.1, J=7.0 \mathrm{~Hz}, 1 \mathrm{H}, \mathrm{H}_{\mathrm{y}}-19\right) ; 1.97$ (s, 3H, H $\left.{ }_{3}-\mathrm{C}(17) \mathrm{OCOCH}_{3}\right) ; 2.40$ (dd, $\left.J=10.8, J=3.6 \mathrm{~Hz}, 1 \mathrm{H}, \mathrm{H}_{\alpha^{-}} 3\right) ; 2.10\left(\mathrm{~m}, 1 \mathrm{H}, \mathrm{H}_{\alpha^{-}} 6\right) ; 2.19$ (ddd, $\left.J=13.5, J=10.0, J=3.3 \mathrm{~Hz}, 1 \mathrm{H}, \mathrm{H}_{\beta}-6\right)$; 2.36 (s, 1H, H-21); 2.40 (dd, $\left.J=10.8, J=3.6 \mathrm{~Hz}, 1 \mathrm{H}, \mathrm{H}_{\alpha}-3\right) ; 2.46\left(\mathrm{td}, J=10.0, J=9.1 \mathrm{~Hz}, 1 \mathrm{H}, \mathrm{H}_{\alpha}-5\right)$; $2.58\left(\mathrm{~s}, 3 \mathrm{H}, \mathrm{H}_{3}-\mathrm{N}(1) \mathrm{CH}_{3}\right) ; 3.11$ (td $\left., J=9.1, J=3.3 \mathrm{~Hz}, 1 \mathrm{H}, \mathrm{H}_{\beta}-5\right) ; 3.19$ (d br, $\left.J=10.8 \mathrm{~Hz}, 1 \mathrm{H}, \mathrm{H}_{\beta}-3\right)$; 3.46 (s, 1H, H-2); 3.67 (s, 3H, H3-C(16) $\left.\mathrm{COOCH}_{3}\right) ; 3.81\left(\mathrm{~s}, 3 \mathrm{H}, \mathrm{H}_{3}-\mathrm{C}(11) \mathrm{OCH}_{3}\right) ; 5.21(\mathrm{~s}, 1 \mathrm{H}, \mathrm{H}-17)$; 6.42 (s, 1H, H-12); 7.36 (s, 1H, H-9); 7.86 (s, 1H, OH). ${ }^{13} \mathrm{C}$ NMR (125 MHz, DMSO-d 6 ) $\delta 7.9$ (C-18); 8.6 (C-22); 11.4 (C-14); 15.8 (C-15); 32.8 (C-19); 20.8 (C-C(17)OCOC_H 3$) ; 38.4$ (C-1); 40.4 (C-20); 44.4 (C-6); $51.7(\mathrm{C}-7) ; 51.8\left(\mathrm{C}-\mathrm{C}(16) \mathrm{COOCH}_{3}\right) ; 52.3(\mathrm{C}-5) ; 52.5(\mathrm{C}-3) ; 56.2\left(\mathrm{C}-\mathrm{C}(11) \underline{O}_{3}\right) ; 69.0(\mathrm{C}-21)$; 76.4 (C-17); 77.9 (C-16); 83.1 (C-2); 94.9 (C-12); 99.0 (C-10); 126.4 (C-9); 127.4 (C-8); 152.9 (C-13); 
$155.9(\mathrm{C}-11) ; 169.9\left(\mathrm{C}-\mathrm{C}(17) \mathrm{OCOCH}_{3}\right) ; 171.6\left(\mathrm{C}-\mathrm{C}(16) \underline{\left.\mathrm{COOCH}_{3}\right)}\right.$. HRMS: $549.15945\left(\mathrm{C}_{26} \mathrm{H}_{34} \mathrm{O}_{6} \mathrm{~N}_{2} \mathrm{Br}\right.$; calc. 549.15948). ESI-MS-MS (rel. int. \%): 489(100); 471(3); 429(7); 401(3); 266(23).

\section{Bromo-17-O-desacetyl-16-des(methoxycarbnyl)vindoline-16-carbohydrazide (9a). 10-Bromo-} vindoline $^{2}(\mathbf{5})(1.16 \mathrm{~g}, 2.17 \mathrm{mmol})$ was dissolved in a mixture of $10 \mathrm{~mL}$ of dry EtOH and $8 \mathrm{~mL}$ of $\mathrm{CHCl}_{3}$. $14 \mathrm{~mL}$ of $64 \%$ hydrazine hydrate was added, then the reaction mixture was stirred at $60{ }^{\circ} \mathrm{C}$ for $72 \mathrm{~h}$ under argon. The solution was evaporated to dryness in vacuo and the residue was dissolved in water $(40 \mathrm{~mL})$ and was extracted with $5 \times 40 \mathrm{~mL}$ of $\mathrm{CHCl}_{3}$. The organic layer was dried with magnesium sulfate and the solvent was evaporated under vacuum. $710 \mathrm{mg}(66 \%)$ of 9a was obtained by preparative thin layer chromatographyy of the residue $\left(\mathrm{CH}_{2} \mathrm{Cl}_{2}-\mathrm{MeOH} 10: 1\right)$, mp 143-145 ${ }^{\circ} \mathrm{C}$. TLC $\left(\mathrm{CH}_{2} \mathrm{Cl}_{2}-\mathrm{MeOH} 10: 1\right), R_{f}=$ 0.36. $[\alpha]^{24}+3.86\left(c 1 ; \mathrm{CH}_{2} \mathrm{Cl}_{2}\right)$. IR (KBr): 3410, 3300, 1670, 1625, 1590, 1490, 1190, 1030, $790 \mathrm{~cm}^{-1}$. ${ }^{1} \mathrm{H}$ NMR (DMSO-d $)$ ) 0.63 (t, 3H, $\left.\mathrm{CH}_{3}-18\right) ; 0.92\left(\mathrm{~m}, 1 \mathrm{H}, \mathrm{CH}_{2}-19 \mathrm{x}\right) ; 1.36\left(\mathrm{~m}, 1 \mathrm{H}, \mathrm{CH}_{2}-19 \mathrm{y}\right) ; 2.16(\mathrm{t}, 2 \mathrm{H}$, $\left.\mathrm{CH}_{2}-6_{\alpha}, 6_{\beta}\right) ; 2.61\left(\mathrm{q}, 1 \mathrm{H}, \mathrm{CH}_{2}-5_{\alpha}\right) ; 2.70(\mathrm{~s}, 1 \mathrm{H}, \mathrm{CH}-21) ; 2.72\left(\mathrm{~s}, 3 \mathrm{H}, \mathrm{N}^{1}-\mathrm{CH}_{3}\right) ; 2.84\left(\mathrm{~d}, 1 \mathrm{H}, \mathrm{CH}_{2}-3_{\mathrm{x}}\right)$; 3.19-3,31 (M, 2H, $\left.\mathrm{CH}_{2}-5_{\beta}, 3 \mathrm{y}\right) ; 3.48$ (s, 1H, CH-2); 3.85 (s, 3H, $\left.\mathrm{CH}_{3} \mathrm{O}-11\right)$; 3.90 (s, 2, CH-17 \& OH-17); 4.28 (s, 2H, NH 2$) ; 5.57$ (d, 1H, CH-15); 5.78 (dd, 1H, CH-14); 6.30 (s, 1H, CH-12); 7.26 (s, 1H, CH-9); 8.57 (s, 1H, NH); 8.83 (s, 1H, OH-17) ppm. HRMS: $493.14431\left(\mathrm{C}_{22} \mathrm{H}_{30} \mathrm{O}_{4} \mathrm{~N}_{4} \mathrm{Br}\right.$; calc. 493.14449). ESI-MS-MS (rel. int. \%): 475(63); 457(3); 443(71); 433(100); 373(12); 266(45); 222(4).

\section{0-Bromo-14,15-dihydro-17-O-desacetyl-16-des(methoxycarbonyl)vindoline-16-carbohydrazide}

(9b). 10-Bromo-14,15-dihydrovindoline (7) (1.36 g, $2.53 \mathrm{mmol})$ was treated with $17 \mathrm{~mL}$ of $64 \%$ hydrazine hydrate in a mixture of $12 \mathrm{~mL}$ of dry $\mathrm{EtOH}$ and $10 \mathrm{~mL}$ of $\mathrm{CHCl}_{3}$ as discussed in the case of hydrazide 9a. $486 \mathrm{mg}(39 \%)$ of $9 \mathbf{b}$ was obtained as a foam. TLC $\left(\mathrm{CH}_{2} \mathrm{Cl}_{2}-\mathrm{MeOH} 10: 1\right), R_{f}=0.53$. $[\alpha]^{32}$ +57.2 (c 1; $\mathrm{CH}_{2} \mathrm{Cl}_{2}$ ). IR (KBr): 3426, 2962, 2938, 1666, 1605, 1496, 1467, 1228, 1041, $880 \mathrm{~cm}^{-1} .1 \mathrm{H}$ NMR $\left(500 \mathrm{MHz}, \mathrm{DMSO}-d_{6}\right) \delta 0.60\left(\mathrm{t}, J=7.4 \mathrm{~Hz}, 3 \mathrm{H}, \mathrm{H}_{3}-18\right) ; 0.64(\mathrm{ABq}, J=13.0, J=7.4 \mathrm{~Hz}, 1 \mathrm{H}$, $\left.\mathrm{H}_{\mathrm{y}}-19\right) ; 0.95\left(\mathrm{ABq}, J=13.0, J=7.4 \mathrm{~Hz}, 1 \mathrm{H}, \mathrm{H}_{\mathrm{x}}-19\right) ; 0.73\left(\mathrm{td}, J=13.0, J=4.4 \mathrm{~Hz}, 1 \mathrm{H}, \mathrm{H}_{\mathrm{ax}}-15\right) ; 1.46(\mathrm{~d}$ br, $\left.J=13.0 \mathrm{~Hz}, 1 \mathrm{H}, \mathrm{H}_{\mathrm{eq}}-14\right) ; 1.80$ (qt, $\left.J=13.0, J=2.8 \mathrm{~Hz}, 1 \mathrm{H}, \mathrm{H}_{\mathrm{ax}}-14\right) ; 1.96$ (m, 1H, $\left.\mathrm{H}_{\alpha}-3\right) ; 2.00$ (s, $1 \mathrm{H}$, $\mathrm{H}-21) ; 2.07$ (d br, $\left.J=13.0 \mathrm{~Hz}, 1 \mathrm{H}, \mathrm{H}_{\mathrm{eq}}-15\right) ; 2.10-2.20$ (m, 2H, $\left.\mathrm{H}_{2}-6\right) ; 2.42$ (q, $\left.J=9.3 \mathrm{~Hz}, 1 \mathrm{H}, \mathrm{H}_{\alpha}-5\right) ; 2.64$ $\left(\mathrm{s}, 3 \mathrm{H}, \mathrm{H}_{3}-\mathrm{N}(1) \mathrm{CH}_{3}\right) ; 3.00\left(\mathrm{~d}\right.$ br, $\left.J=10.0 \mathrm{~Hz}, 1 \mathrm{H}, \mathrm{H}_{\beta}-3\right) ; 3.06(\mathrm{ddd} b r, J=9.3, J=7.7, J=2.3 \mathrm{~Hz}, 1 \mathrm{H}$, $\left.\mathrm{H}_{\beta}-5\right) ; 3.33$ (s, 1H, H-2); 3.78 (s, 3H, $\left.\mathrm{H}_{3}-\mathrm{C}(11) \mathrm{OCH}_{3}\right) ; 4.11$ (d, $\left.J=7.3 \mathrm{~Hz}, 1 \mathrm{H}, \mathrm{OH}-17\right) ; 4.22(\mathrm{~d}, J=7.3$ Hz, 1H, H-17); 4.26 (br, 2H, NH 2$) 6.35$ (s, 1H, H-12); 7.20 (s, 1H, H-9); 8.80 (s, 1H, NH); 9.09 (s, 1H, $\mathrm{OH}) .{ }^{13} \mathrm{C}$ NMR (125 MHz, DMSO-d 6 ) $\delta 7.7$ (C-18); 22.9 (C-14); 29.9 (C-15); 34.8 (C-19); 39.1 (C-1); 39.6 (C-20); 45.0 (C-6); 51.4 (C-3); 52.0 (C-5); 52.2 (C-7); 56.2 (C-C(11)OC_H $)_{3}$; 70.1 (C-17); 75.4 (C-21); 78.8 (C-16); 85.2 (C-2); 94.9 (C-12); 98.5 (C-10); 126.3 (C-9); 128.9 (C-8); 154.2 (C-13); 155.7 
(C-11); 172.1 (C-C(16)ㅡNHNH 2 ). HRMS: $495.15995\left(\mathrm{C}_{22} \mathrm{H}_{32} \mathrm{O}_{4} \mathrm{~N}_{4} \mathrm{Br}\right.$; calc. 495.16014). ESI-MS-MS (rel. int. \%): 477(35); 459(3); 445(14); 435(100); 266(19).

\section{0-Bromo-14(S),15(R)-cyclopropano-17-O-desacetyl-16-des(methoxycarbonyl)vindoline-16-carbo-} hydrazide (9c). 10-Bromo-14,15-cyclopropanovindoline (8) (882 mg, $1.605 \mathrm{~mol})$ was treated with $10 \mathrm{~mL}$ of $64 \%$ hydrazine hydrate in dry EtOH $(10 \mathrm{~mL})$ for $24 \mathrm{~h}$ as discussed in the case of hydrazide $9 \mathrm{a} .444 \mathrm{mg}$ $(55 \%)$ of $9 \mathrm{c}$ was obtained which was used in further reactions without any purification. ${ }^{1} \mathrm{H}$ NMR (500 $\left.\mathrm{MHz}, \mathrm{DMSO}-d_{6}\right) \delta 0.52\left(\mathrm{~m}, 2 \mathrm{H}, \mathrm{H}_{\alpha^{-}}-15, \mathrm{H}_{\mathrm{x}}-22\right) ; 0.79\left(\mathrm{t}, J=7.3 \mathrm{~Hz}, 3 \mathrm{H}, \mathrm{H}_{3}-18\right) ; 0.84(\mathrm{ABq}, J=13.4, J=$ $\left.7.3 \mathrm{~Hz}, 1 \mathrm{H}, \mathrm{H}_{\mathrm{x}}-19\right) ; 0.92\left(\mathrm{~m}, 1 \mathrm{H}, \mathrm{H}_{\mathrm{y}}-22\right) ; 1.12$ (m, 1H, $\left.\mathrm{H}_{\alpha}-14\right) ; 1.28$ (ABq, $J=13.4, J=7.3 \mathrm{~Hz}, 1 \mathrm{H}$, $\left.\mathrm{H}_{\mathrm{y}}-19\right) ; 2.01$ (m, 1H, $\left.\mathrm{H}_{\alpha^{-}}-6\right) ; 2.08$ (ddd, $\left.J=13.9, J=10.3, J=3.9 \mathrm{~Hz}, 1 \mathrm{H}, \mathrm{H}_{\beta}-6\right) ; 2.28$ (s, 1H, H-21); 2.42 $\left(\mathrm{m}, 2 \mathrm{H}, \mathrm{H}_{\alpha^{-}} 3, \mathrm{H}_{\alpha^{-}}-5\right) ; 2.65$ (s, 3H, $\left.\mathrm{H}_{3}-\mathrm{N}(1) \mathrm{CH}_{3}\right) ; 3.06$ (td, $\left.J=9.2, J=3.9 \mathrm{~Hz}, 1 \mathrm{H}, \mathrm{H}_{\beta}-5\right) ; 3.18(\mathrm{~m}, 1 \mathrm{H}$, $\left.\mathrm{H}_{\beta}-3\right) ; 3.29$ (s, 1H, H-2); 3.56 (d, 1H, C(17)OH) 3.79 (s, 3H, $\left.\mathrm{H}_{3}-\mathrm{C}(11) \mathrm{OCH}_{3}\right) ; 3.95$ (d, 1H, H-17); 4.27 (s br, 2H, NH 2$) ; 6.30$ (s, 1H, H-12); 7.23 (s, 1H, H-9); 7.81 (s, 1H, C(16)OH); $8.91(\mathrm{~s}, 1 \mathrm{H}, \mathrm{NH}) .{ }^{13} \mathrm{C}$ NMR (125 MHz, DMSO- $d_{6}$ ) $\delta 7.9$ (C-18); 8.2 (C-22); 11.0 (C-14); 15.0 (C-15); 35.9 (C-19); 38.3 (C-1); 40.1 (C-20); 45.2 (C-6); 51.7 (C-7); 52.0 (C-5); 52.5 (C-3); 56.1 (C-C(11)OC_H $)_{3}$; 70.8 (C-21); 73.0 (C-17); 78.7 (C-16); 84.2 (C-2); 94.0 (C-12); 97.7 (C-10); 126.1 (C-9); 127.5 (C-8); 153.0 (C-13); 155.8 (C-11); $171.2(\mathrm{C}-\mathrm{C}(16) \underline{\mathrm{CONHNH}} 2)$. HRMS: $507.16017\left(\mathrm{C}_{23} \mathrm{H}_{32} \mathrm{O}_{4} \mathrm{~N}_{4} \mathrm{Br}\right.$; calc. 507.16014). ESI-MS-MS (rel. int. \%): 489(45); 472(4); 457(19); 447(50); 417(4); 389(100); 266(29); 240(2).

\section{General method for coupling [10-bromo-17-O-desacetyl-16-des(methoxycarbonyl)vindoline-16- carbonyl]azides with tryptophan methyl esters}

\section{Methyl \{ $N$-[10-bromo-17- $O$-desacetyl-16-des(methoxycarbonyl)vindoline-16-carbonyl]-L-trypto-}

phanate (11a). Hydrazide 9a $(250 \mathrm{mg}, 0.51 \mathrm{mmol})$ was dissolved in a mixture of $\mathrm{MeOH}(8 \mathrm{~mL})$ and $1 \mathrm{~N}$ hydrochloric acid $(29 \mathrm{~mL})$, and at $-12{ }^{\circ} \mathrm{C}$ sodium nitrite $(81 \mathrm{mg}, 1.17 \mathrm{mmol})$ was added. After stirring for $10 \mathrm{~min}$, the $\mathrm{pH}$ of the reaction mixture was adjusted to 8-8.5 with saturated aqueous sodium hydrogen carbonate. Then the solution was extracted with $\mathrm{CH}_{2} \mathrm{Cl}_{2}(4 \times 20 \mathrm{~mL})$, the organic layer was washed with brine and dried with magnesium sulfate. Subsequently the $\mathrm{CH}_{2} \mathrm{Cl}_{2}$ solution was concentrated to $1 / 4$ part and the azide (10a) was used without isolation in the coupling reaction with L-tryptophan methyl ester (0.51 mmol) in $\mathrm{CH}_{2} \mathrm{Cl}_{2}(2 \mathrm{~mL})$. The reaction mixture was kept in a refrigerator at $4{ }^{\circ} \mathrm{C}$ for a week. The dark solution was washed with water $(8 \mathrm{ml})$ and dried with magnesium sulfate. The solvent was evaporated in vacuum and the residue was purified by preparative thin-layer chroatography $\left(\mathrm{CH}_{2} \mathrm{Cl}_{2}-\mathrm{MeOH} 20: 1\right) .190 \mathrm{mg}(55 \%)$ of 11a was isolated, mp 133-134 ${ }^{\circ} \mathrm{C}$, $\mathrm{HCl}$ salt of 11a, mp 178-181 ${ }^{\circ} \mathrm{C}$. TLC $\left(\mathrm{CH}_{2} \mathrm{Cl}_{2}-\mathrm{MeOH} 20: 1\right), R_{f}=0.40 .[\alpha]^{20}{ }_{\mathrm{D}}-18.1(c 1 ; \mathrm{MeOH} ; 11 \mathbf{a} . \mathrm{HCl})$. 
IR (KBr):3400, 2960, 1740, 1660, 1500, 1250, 1030, $740 \mathrm{~cm}^{-1} .{ }^{1} \mathrm{H}$ NMR (DMSO-d $): 0.55(\mathrm{t}, 3 \mathrm{H}$, $\left.\mathrm{CH}_{3}-18\right) ; 0.97\left(\mathrm{~m}, 1 \mathrm{H}, \mathrm{CH}_{2}-19 \mathrm{x}\right) ; 1.40\left(\mathrm{~m}, 1 \mathrm{H}, \mathrm{CH}_{2}-19 \mathrm{y}\right) ; 1.99$ (s, 1H, CH-21); 2.33-2.59 (m, 3H, $\left.\mathrm{CH}_{2}-5_{\alpha}, 6_{\alpha}, 6_{\beta}\right) ; 2.61\left(\mathrm{~s}, 3 \mathrm{H}, \mathrm{N}^{1}-\mathrm{CH}_{3}\right) ; 3.16-3.78\left(\mathrm{~m}, 3 \mathrm{H}, \mathrm{CH}_{2}-5_{\beta}, 6_{\alpha}, 6_{\beta}\right) ; 3.56\left(\mathrm{~s}, 3 \mathrm{H}, \mathrm{CH}_{3} \mathrm{O}-11\right) ; 3.66(\mathrm{~s}, 1 \mathrm{H}$, $\mathrm{CH}-2) ; 3.81$ (s, 3H, $\left.\mathrm{CH}_{3}-36\right) ; 4.15$ (s, 1H, CH-17); 4.63 (d, 1H, CH-24); 5.72 (d, 1H, CH-15); 5.85 (dd, 1H, CH-14); 6.37 (s, 1H, CH-12); 6.99 (t, 1H, CH-33); 7.06 (t, 1H, CH-32); 7.31 (s, 1H, CH-27); 7.36 (d, 1H, CH-34); 7.48 (d, 1H, CH-31); 7.54 (s, 1H, CH-9); 8.18 (d, 1H, NH-23); 8.96 (s, 1H, OH-16); 11.02 (s, 1H, indol NH-28) ppm. HRMS: $679.21261\left(\mathrm{C}_{34} \mathrm{H}_{40} \mathrm{O}_{6} \mathrm{~N}_{4} \mathrm{Br}\right.$; calc. 679.21257). ESI-MS-MS (rel. int. \%): 661(100); 619(5); 443(85); 433(78); 408(6); 373(18); 266(31).

\section{Methyl \{ $N$-[10-bromo-17- $O$-desacetyl-16-des(methoxycarbonyl)vindoline-16-carbonyl]-D-trypto-}

phanate\} (11c). Hydrazide 9a $(250 \mathrm{mg}, 0.51 \mathrm{mmol})$ was converted to the azide (10a) which was treated with D-tryptophan methyl ester $(0.51 \mathrm{mmol})$ as discussed in the case of compound 11a. $90 \mathrm{mg}(26 \%)$ of 11c was isolated, $\mathrm{mp} 137-138{ }^{\circ} \mathrm{C}$. TLC: $\mathrm{CH}_{2} \mathrm{Cl}_{2}-\mathrm{MeOH} 20: 1 . R_{f}=0.30$. [ $\left.\alpha\right]^{23} \mathrm{D}-1.1\left(c 1 ; \mathrm{CH}_{2} \mathrm{Cl}_{2}\right)$. IR (KBr): 3400, 2980, 2940, 1750, 1680, 1620, 1500, 1230, 1050, 880, 820, $750 \mathrm{~cm}^{-1} .{ }^{1} \mathrm{H}$ NMR $(500 \mathrm{MHz}$, DMSO- $\left.d_{6}\right) \delta 0.56\left(\mathrm{t}, J=7.3,3 \mathrm{H}, \mathrm{H}_{3}-18\right) ; 0.80\left(\mathrm{ABq}, J=14.0 J=7.3 \mathrm{~Hz}, 1 \mathrm{H}, \mathrm{H}_{\mathrm{x}}-19\right) ; 1.21(\mathrm{ABq}, J=$ 14.0, $\left.J=7.3 \mathrm{~Hz}, 1 \mathrm{H}, \mathrm{H}_{\mathrm{y}}-19\right) ; 1.99\left(\mathrm{~m}, 1 \mathrm{H}, \mathrm{H}_{\alpha}-6\right) ; 2.06\left(\mathrm{~m}, 1 \mathrm{H}, \mathrm{H}_{\beta}-6\right) ; 2.09$ (s, 3H, $\left.\mathrm{H}_{3}-\mathrm{N}(1) \mathrm{CH}_{3}\right) ; 2.57$ (ddd, $\left.J=9.7, J=9.0, J=7.4 \mathrm{~Hz}, 1 \mathrm{H}, \mathrm{H}_{\alpha}-5\right) ; 2.61$ (s, 1H, H-21); 2.79 (d, $\left.J=16.1 \mathrm{~Hz}, 1 \mathrm{H}, \mathrm{H}_{\alpha^{-}}-3\right) ; 3.03$ (s, $1 \mathrm{H}, \mathrm{H}-2) ; 3.19$ (m, 2H, $\mathrm{H}_{2}-1$ ”); 3.22 (td, $\left.J=9.0, J=4.0 \mathrm{~Hz}, 1 \mathrm{H}, \mathrm{H}_{\beta}-5\right) ; 3.35$ (m, 1H, $\mathrm{H}_{\beta}-3$ ); 3.60 (s, 3H, $\mathrm{H}_{3}-\mathrm{C}\left(3\right.$ ”) $\left.\mathrm{OOCH}_{3}\right) ; 3.74$ (s, 3H, $\left.\mathrm{H}_{3}-\mathrm{C}(11) \mathrm{OCH}_{3}\right) ; 3.76$ (d, $\left.J=7.4 \mathrm{~Hz}, 1 \mathrm{H}, \mathrm{H}-17\right) ; 3.96$ (d, J = 7.2 Hz, 1H, $\mathrm{C}(17) \mathrm{OH}) ; 4.57$ (ddd, $1 \mathrm{H}, J=8.5, J=7.3 \mathrm{~Hz}, J=6.4 \mathrm{~Hz}, \mathrm{H}-2$ ”); 5.50 (d, $J=10.4 \mathrm{~Hz}, 1 \mathrm{H}, \mathrm{H}-15) ; 5.74$ (ddd, $J=10.4, J=5.1, J=1.2 \mathrm{~Hz}, 1 \mathrm{H}, \mathrm{H}-14) ; 6.14$ (s, 1H, H-12); 7.00 (ddd, $J=7.7 \mathrm{~Hz}, J=7.0, J=0.9$ Hz, 1H, H-5'); 7.05 (ddd, $J=7.9, J=7.0, J=0.9$ Hz, 1H, H-6'); 7.20 (s, 1H, H-9); 7.25 (d, $J=2.2$ Hz, $1 \mathrm{H}, \mathrm{H}-2^{\prime}$ ); 7.31 (dt, $\left.J=7.9, J=0.9 \mathrm{~Hz}, 1 \mathrm{H}, \mathrm{H}-7^{\prime}\right) ; 7.57$ (d, $J=7.7 \mathrm{~Hz}, 1 \mathrm{H}, \mathrm{H}-6$ '); 7.86 (d, $J=8.4 \mathrm{~Hz}$, $1 \mathrm{H}, \mathrm{H}-4$ "); 8.97 (s, 1H, C(16)OH); 10.88 (d, $J=2.2 \mathrm{~Hz}, 1 \mathrm{H}, \mathrm{H}-1$ '). ${ }^{13} \mathrm{C}$ NMR (125 MHz, DMSO-d $\left.d_{6}\right) \delta$ 7.5 (C-18); 27.5 (C-1”); 32.0 (C-19); 37.5 (C-1); 42.3 (C-20); 44.5 (C-6); 50.3(C-3); 50.5 (C-5); 51.9

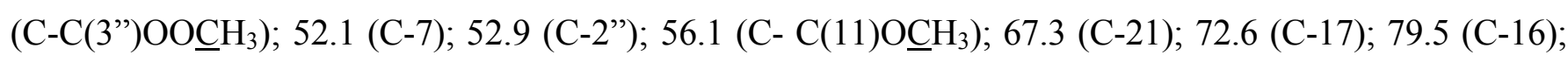
83.4 (C-2); 93.7 (C-12); 97.3 (C-10); 109.4 (C-3’); 111.4 (C-7’); 118.2 (C-4'); 118.4 (C-5’); 121.0 (C-6’); 122.6 (C-14); 124.0 (C-2'); 126.1 (C-9); 126.6 (C-8); 127.3 (C-3a'); 131.5 (C-15); 136.1 (C-7a'); 153.0 (C-13); 155.8 (C-11); 172.0 (C-C(16)ㅡNH); 172.1 (C-3”). HRMS: $679.21253\left(\mathrm{C}_{34} \mathrm{H}_{40} \mathrm{O}_{6} \mathrm{~N}_{4} \mathrm{Br}\right.$; calc. 679.21257). ESI-MS-MS (rel. int. \%): 661(100); 618(10); 443(58); 433(65); 408(6); 373(22); 266(33).

\section{Methyl \{ $N$-[10-bromo-14,15-dihydro-17-O-desacetyl-16-des(methoxycarbonyl)vindoline-16-}

carbonyl]-L-tryptophanate\} (11e). Hydrazide 9b (254 $\mathrm{mg}, 0.51 \mathrm{mmol})$ was converted to the corresponding azide which was treated with L-tryptophan methyl ester $(0.51 \mathrm{mmol})$ as discussed in the 
case of compound 11a. $115 \mathrm{mg}(33 \%)$ of 11e was isolated. TLC: $\mathrm{CH}_{2} \mathrm{Cl}_{2}-\mathrm{MeOH} 10: 1 . R_{f}=0.54$. $[\alpha]^{32}$ +30.8 ( c 0.5; $\mathrm{CH}_{2} \mathrm{Cl}_{2}$ ). IR (KBr): 3405, 2945, 1742, 1667, 1605, 1496, 1356, 1340, 1254, 1177, 880, 813, $743 \mathrm{~cm}^{-1} .{ }^{1} \mathrm{H}$ NMR $\left(800 \mathrm{MHz}, \mathrm{DMSO}-d_{6}\right) \delta 0.55\left(\mathrm{t}, J=7.3 \mathrm{~Hz}, 3 \mathrm{H}, \mathrm{H}_{3}-18\right) ; 0.65(\mathrm{ABq}, J=13.7, J=7.3$ $\left.\mathrm{Hz}, 1 \mathrm{H}, \mathrm{H}_{\mathrm{x}}-19\right) ; 0.70$ (td, $\left.J=13.6, J=4.2 \mathrm{~Hz}, 1 \mathrm{H}, \mathrm{H}_{\mathrm{ax}}-15\right)$; 0.95 (ABq, $\left.J=13.7, J=7.3 \mathrm{~Hz}, 1 \mathrm{H}, \mathrm{H}_{\mathrm{y}}-19\right)$; 1.49 (dqi, $\left.J=13.1, J=3.3 \mathrm{~Hz}, 1 \mathrm{H}, \mathrm{H}_{\mathrm{eq}}-14\right) ; 1.78$ (qt, $\left.J=13.1, J=3.9 \mathrm{~Hz}, 1 \mathrm{H}, \mathrm{H}_{\mathrm{ax}}-14\right) ; 1.95$ (ddd, $J=$ $\left.13.1, J=11.0, J=2.4 \mathrm{~Hz}, 1 \mathrm{H}, \mathrm{H}_{\mathrm{ax}}-3\right) ; 2.03$ (s, 1H, H-21); 2.07 (d, $\left.J=13.6 \mathrm{~Hz}, 1 \mathrm{H}, \mathrm{H}_{\mathrm{eq}}-15\right) ; 2.09-2.18$ (m, 2H, $\mathrm{H}_{2}-6$ ); 2.43 (q, $\left.J=9.5 \mathrm{~Hz}, 1 \mathrm{H}, \mathrm{H}_{\alpha}-5\right) ; 2.62\left(\mathrm{~s}, 3 \mathrm{H}, \mathrm{H}_{3}-\mathrm{N}(1) \mathrm{CH}_{3}\right) ; 3.03$ (d, $J=11.0 \mathrm{~Hz}, 1 \mathrm{H}$, $\left.\mathrm{H}_{\mathrm{eq}}-3\right) ; 3.07$ (td, $\left.J=9.5, J=2.0 \mathrm{~Hz}, 1 \mathrm{H}, \mathrm{H}_{\beta}-5\right) ; 3.20$ (ABd, $J=14.7, J=6.1 \mathrm{~Hz}, 1 \mathrm{H}, \mathrm{H}_{\mathrm{x}}-1$ ”); 3.25 (ABd, $J=14.7, J=6.1 \mathrm{~Hz}, 1 \mathrm{H}, \mathrm{H}_{\mathrm{x}}-1$ ”); 3.30 (s, 1H, H-2); 3.55(s, 3H, $\left.\mathrm{H}_{3}-\mathrm{C}\left(3{ }^{\prime \prime}\right) \mathrm{OOCH}_{3}\right) ; 3.78\left(\mathrm{~s}, 3 \mathrm{H}, \mathrm{H}_{3}-\right.$ $\left.\mathrm{C}(11) \mathrm{OCH}_{3}\right) ; 4.24$ (d, $\left.J=7.6 \mathrm{~Hz}, 1 \mathrm{H}, \mathrm{H}-17\right) ; 4.38$ (d, $\left.J=7.6 \mathrm{~Hz}, 1 \mathrm{H}, \mathrm{C}(17) \mathrm{OH}\right) ; 4.64$ (dt, $1 \mathrm{H}, J=7.3, J$ $=6.1 \mathrm{~Hz}, \mathrm{H}-2$ "); 6.34 (s, 1H, H-12); 6.99 (ddd, $J=7.8, J=7.0, J=0.9 \mathrm{~Hz}, 1 \mathrm{H}, \mathrm{H}-5$ '); 7.08 (ddd, $J=8.1$, $J=7.0, J=1.1 \mathrm{~Hz}, 1 \mathrm{H}, \mathrm{H}-6$ '); 7.20 (s, 1H, H-9); 7.26 (d, $J=2.3 \mathrm{~Hz}, 1 \mathrm{H}, \mathrm{H}-2$ '); 7.35 (dt, $J=8.1, J=0.8$ Hz, 1H, H-7'); 7.57 (d, $J=7.8$ Hz, 1H, H-6'); 7.88 (d, J = 7.3 Hz, 1H, H-4’); 9.49 (s, 1H, C(16)OH); 10.91 (d, $J=2.4 \mathrm{~Hz}, 1 \mathrm{H}, \mathrm{H}-1$ '). ${ }^{13} \mathrm{C}$ NMR (200 MHz, DMSO-d $) \delta 7.7$ (C-18); 23.0 (C-14); 27.2 (C-1");

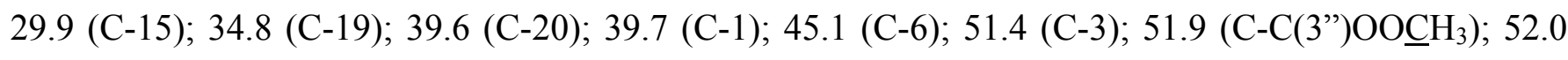
(C-5); 52.5 (C-2”); 52.8 (C-7); $56.3\left(\mathrm{C}-\mathrm{C}(11) \mathrm{OCH}_{3}\right) ; 70.4$ (C-17); 75.4 (C-21); 79.2 (C-16); 85.1 (C-2); 95.0 (C-12); 98.6 (C-10); 108.7 (C-3’); 111.5 (C-7'); 118.3 (C-4'); 118.6 (C-5'); 121.1 (C-6'); 124.3 (C-2'); 126.4 (C-9); 127.3 (C-3a'); 128.8 (C-8); 136.2 (C-7a'); 154.4 (C-13); 155.8 (C-11); 172.2 (C-C(16)ㅡNH); 173.6 (C-3”). HRMS: $681.22855\left(\mathrm{C}_{34} \mathrm{H}_{42} \mathrm{O}_{6} \mathrm{~N}_{4} \mathrm{Br}\right.$; calc. 681.22822). ESI-MS-MS (rel. int. \%): 663(83); 621(2); 463(2); 445(21); 435(100); 417(4); 410(2); 266(12).

\section{Methyl $\{\mathrm{N}$-[10-bromo-14,15-dihydro-17-O-desacetyl-16-des(methoxycarbonyl)vindoline-16-}

carbonyl]-D-tryptophanate\} (11g). Compound $11 \mathrm{~g}$ (118 $\mathrm{mg}$, 34\% yield) was prepared analogously with compound 11e, mp $152{ }^{\circ} \mathrm{C}$. TLC: $\mathrm{CH}_{2} \mathrm{Cl}_{2}-\mathrm{MeOH} 10: 1 . R_{f}=0.54 .[\alpha]^{32}{ }_{\mathrm{D}}+45.4\left(c 0.5 ; \mathrm{CH}_{2} \mathrm{Cl}_{2}\right)$. IR $(\mathrm{KBr})$ : $3397,2946,1740,1670,1604,1496,1355,1341,1254,1177,880,813,743 \mathrm{~cm}^{-1} .{ }^{1} \mathrm{H}$ NMR $(800 \mathrm{MHz}$, DMSO- $\left.d_{6}\right) \delta 0.55\left(\mathrm{t}, J=7.3 \mathrm{~Hz}, 3 \mathrm{H}, \mathrm{H}_{3}-18\right) ; 0.57$ (ABq, $\left.J=13.7 J=7.3 \mathrm{~Hz}, 1 \mathrm{H}, \mathrm{H}_{\mathrm{x}}-19\right) ; 0.70(\mathrm{td}, J=$ $\left.13.6, J=4.2 \mathrm{~Hz}, 1 \mathrm{H}, \mathrm{H}_{\mathrm{ax}}-15\right) ; 0.85\left(\mathrm{ABq}, J=13.7, J=7.3 \mathrm{~Hz}, 1 \mathrm{H}, \mathrm{H}_{\mathrm{y}}-19\right) ; 1.45$ (dqi, $J=13.2, J=3.6$ $\left.\mathrm{Hz}, 1 \mathrm{H}, \mathrm{H}_{\mathrm{eq}}-14\right) ; 1.78$ (qt, $\left.J=13.2, J=3.9 \mathrm{~Hz}, 1 \mathrm{H}, \mathrm{H}_{\mathrm{ax}}-14\right) ; 1.95$ (m, 1H, $\left.\mathrm{H}_{\mathrm{ax}}-3\right) 1.96$ (s, 1H, H-21); 1.99-2.12 (m, 3H, $\left.\mathrm{H}_{2}-6, \mathrm{H}_{\mathrm{eq}}-15\right) ; 2.12$ (s, 3H, $\left.\mathrm{H}_{3}-\mathrm{N}(1) \mathrm{CH}_{3}\right) ; 2.41$ (q, J = 9.5 Hz, 1H, $\left.\mathrm{H}_{\alpha}-5\right) ; 2.96$ (s, $1 \mathrm{H}$, H-2); 3.00 (d, $\left.J=10.6 \mathrm{~Hz}, 1 \mathrm{H}, \mathrm{H}_{\mathrm{eq}}-3\right) ; 3.06$ (td, $\left.J=9.5, J=1.5 \mathrm{~Hz}, 1 \mathrm{H}, \mathrm{H}_{\beta}-5\right) ; 3.20$ (m, 2H, $\mathrm{H}_{2}-1$ ”); 3.63 (s, 3H, $\mathrm{H}_{3}-\mathrm{C}\left(3\right.$ ”) $\left.\mathrm{OOCH}_{3}\right) ; 3.74$ (s, 3H, H3-C(11) $\left.\mathrm{OCH}_{3}\right) ; 4.12$ (d, $\left.J=7.5 \mathrm{~Hz}, 1 \mathrm{H}, \mathrm{H}-17\right) ; 4.23$ (d, $J=7.5$ $\mathrm{Hz}, 1 \mathrm{H}, \mathrm{C}(17) \mathrm{OH}) ; 4.62$ (ddd, 1H, $J=8.5, J=7.1, J=6.4 \mathrm{~Hz}, \mathrm{H}-2$ ”); 6.23 (s, 1H, H-12); 7.00 (ddd, $J=$ $7.8, J=7.0, J=0.8 \mathrm{~Hz}, 1 \mathrm{H}, \mathrm{H}-5$ '); 7.06 (ddd, $J=8.0, J=7.0, J=1.1 \mathrm{~Hz}, 1 \mathrm{H}, \mathrm{H}-6$ '); 7.17 (s, 1H, H-9); $7.23\left(\mathrm{~d}, J=2.4 \mathrm{~Hz}, 1 \mathrm{H}, \mathrm{H}-2^{\prime}\right) ; 7.33$ (dt, $\left.J=8.0, J=0.8 \mathrm{~Hz}, 1 \mathrm{H}, \mathrm{H}-7^{\prime}\right) ; 7.57$ (d, $J=7.8 \mathrm{~Hz}, 1 \mathrm{H}, \mathrm{H}-6$ '); 
7.87 (d, $J=8.5 \mathrm{~Hz}, 1 \mathrm{H}, \mathrm{H}-4$ ”); 9.44 (s, 1H, C(16)OH); 10.88 (d, $J=2.4 \mathrm{~Hz}, 1 \mathrm{H}, \mathrm{H}-1$ '). ${ }^{13} \mathrm{C}$ NMR $(200$ MHz, DMSO-d 6 ) $\delta 7.7$ (C-18); 22.9 (C-14); 27.7 (C-1”); 29.9 (C-15); 34.8 (C-19); 38.8 (C-1); 39.7 (C-20); 45.1 (C-6); 51.4 (C-3); 52.0 (C-5); 52.1 (C-C(3”)OOCLH $\left.{ }_{3}\right) ; 52.4$ (C-7); 53.2 (C-2”); 56.3 (C$\left.\mathrm{C}(11) \mathrm{OCH}_{3}\right) ; 70.0$ (C-17); 75.5 (C-21); 79.1 (C-16); 84.9 (C-2); 95.0 (C-12); 98.6 (C-10); 109.5 (C-3'); 111.6 (C-7'); 118.3 (C-4'); 118.6 (C-5'); 121.2 (C-6'); 124.2 (C-2'); 126.4 (C-9); 127.4 (C-3a'); 128.9 (C-8); 136.3 (C-7a'); 154.3 (C-13); 155.8 (C-11); 172.4 (C-C(16)ㅡNH); 173.4 (C-3”). HRMS: 681.22813 $\left(\mathrm{C}_{34} \mathrm{H}_{42} \mathrm{O}_{6} \mathrm{~N}_{4} \mathrm{Br}\right.$; calc. 681.22822). ESI-MS-MS (rel. int. \%): 663(1); 621(3); 463(2); 445(24); 435(100); 417(4); 266(15).

\section{Methyl $\{N$-[10-bromo-14(S),15(R)-cyclopropano-17-O-desacetyl-16-des(methoxycarbonyl)vindoline-}

16-carbonyl]-L-tryptophanate\} (11i). Hydrazide 9c (254 $\mathrm{mg}, 0.50 \mathrm{mmol})$ was converted to the corresponding azide which was treated with L-tryptophan methyl ester $(0.50 \mathrm{mmol})$ as discussed in the case of compound 11a. $168 \mathrm{mg}(48 \%)$ of $11 \mathrm{i}$ was isolated, mp 148-150 ${ }^{\circ} \mathrm{C}$. TLC: $\mathrm{CH}_{2} \mathrm{Cl}_{2}-\mathrm{MeOH} 20: 1 . R_{f}$ $=0.41 .[\alpha]^{29}{ }_{\mathrm{D}}+20.2\left(c 1 ; \mathrm{CH}_{2} \mathrm{Cl}_{2}\right.$ ). IR (KBr): 3406, 1742, 1669, 1603, 1497, 1458, 1230, 1042, $743 \mathrm{~cm}^{-1}$. ${ }^{1} \mathrm{H}$ NMR $\left(800 \mathrm{MHz}, \mathrm{DMSO}-d_{6}\right) \delta 0.53\left(\mathrm{~m}, 1 \mathrm{H}, \mathrm{H}_{\alpha}-15\right) ; 0.64\left(\mathrm{~m}, 1 \mathrm{H}, \mathrm{H}_{\mathrm{x}}-22\right) ; 0.79(\mathrm{t}, J=7.3 \mathrm{~Hz}, 3 \mathrm{H}$, $\left.\mathrm{H}_{3}-18\right) ; 0.87\left(\mathrm{ABq}, J=13.4, J=7.3 \mathrm{~Hz}, 1 \mathrm{H}, \mathrm{H}_{\mathrm{x}}-19\right) ; 0.98$ (q, $\left.1 \mathrm{H}, J=5.3 \mathrm{~Hz}, \mathrm{H}_{\mathrm{y}}-22\right) ; 1.16(\mathrm{~m}, 1 \mathrm{H}$, $\left.\mathrm{H}_{\alpha^{-}}-14\right) ; 1.29$ (ABq, $\left.J=13.4, J=7.3 \mathrm{~Hz}, 1 \mathrm{H}, \mathrm{H}_{\mathrm{y}}-19\right) ; 1.99$ (dt, $\left.J=13.4, J=8.2 \mathrm{~Hz}, 1 \mathrm{H}, \mathrm{H}_{\alpha^{-}}-6\right) ; 2.07$ (ddd, $\left.J=13.4, J=10.5, J=4.3 \mathrm{~Hz}, 1 \mathrm{H}, \mathrm{H}_{\beta}-6\right) ; 2.34$ (s, $\left.1 \mathrm{H}, \mathrm{H}-21\right) ; 2.43\left(\mathrm{~m}, 1 \mathrm{H}, \mathrm{H}_{\alpha}-5\right) ; 2.45$ (dd, $J=10.7, J=$ $\left.3.6 \mathrm{~Hz}, 1 \mathrm{H}, \mathrm{H}_{\alpha}-3\right) ; 2.64$ (s, $\left.3 \mathrm{H}, \mathrm{H}_{3}-\mathrm{N}(1) \mathrm{CH}_{3}\right) ; 3.06$ (td , $\left.J=9.2, J=4.3 \mathrm{~Hz}, 1 \mathrm{H}_{,} \mathrm{H}_{\beta}-5\right) ; 3.18$ (d, $J=10.7$ $\left.\mathrm{Hz}, 1 \mathrm{H}, \mathrm{H}_{\beta}-3\right)$; 3.20 and 3.25 (ABd, $J=14.8, J=5.8 \mathrm{~Hz}, 2 \mathrm{H}, \mathrm{H}_{2}-1$ "); 3.26 (s, 1H, H-2); 3.56 (s, 3H, $\mathrm{H}_{3}-\mathrm{C}\left(3\right.$ ”) $\left.\mathrm{OOCH}_{3}\right) ; 3.74$ (d, $\left.J=7.8 \mathrm{~Hz}, 1 \mathrm{H}, \mathrm{C}(17) \mathrm{OH}\right) ; 3.79$ (s, $\left.3 \mathrm{H}, \mathrm{H}_{3}-\mathrm{C}(11) \mathrm{OCH}_{3}\right) ; 3.97$ (d, $J=7.8 \mathrm{~Hz}$, $1 \mathrm{H}, \mathrm{H}-17) ; 4.66$ (dt, 1H, $J=7.6, J=5.8 \mathrm{~Hz}, \mathrm{H}-2$ ”); 6.28 (s, 1H, H-12); 6.99 (ddd, $J=7.9, J=7.0, J=$ $0.9 \mathrm{~Hz}, 1 \mathrm{H}, \mathrm{H}-5$ '); 7.07 (ddd, $J=8.1, J=7.0, J=0.9 \mathrm{~Hz}, 1 \mathrm{H}, \mathrm{H}-6$ '); 7.24 (s, 1H, H-9); 7.26 (d, $J=2.5$ Hz, 1H, H-2'); 7.34 (dt, $J=8.1, J=0.9$ Hz, 1H, H-7'); 7.52 (d, $J=7.9$ Hz, 1H, H-6'); 7.81 (d, $J=7.6$ $\mathrm{Hz}, 1 \mathrm{H}, \mathrm{H}-4$ "); 8.26 (s, 1H, C(16)OH); 10.93 (d, $J=2.5 \mathrm{~Hz}, 1 \mathrm{H}, \mathrm{H}-1$ '). ${ }^{13} \mathrm{C}$ NMR (200 MHz, DMSO- $\left.d_{6}\right)$ $\delta 7.8$ (C-18); 8.2 (C-22); 11.1 (C-14); 15.0 (C-15); 27.1 (C-1”); 35.7 (C-19); 38.8 (C-1); 40.0 (C-20); 45.0 (C-6); 51.7 (C-5); 51.8 (C-C(3”)OOCLH 3 ); 51.9 (C-7); 52.4 (C-3, C-2”); 56.1 (C-C(11)OC_H 3$) ; 70.6(\mathrm{C}-21)$; 73.1 (C-17); 79.0 (C-16); 83.9 (C-2); 94.0 (C-12); 97.7 (C-10); 108.5 (C-3’); 111.3 (C-7'); 118.3 (C-4'); 118.4 (C-5'); 120.9 (C-6'); 124.2 (C-2'); 126.1 (C-9); 127.2 (C-8); 127.3 (C-3a'); 136.0 (C-7a'); 153.2 (C-13); 155.8 (C-11); 171.8 (C-3”); 172.0 (C-C(16)ONH). HRMS: $693.22832\left(\mathrm{C}_{35} \mathrm{H}_{42} \mathrm{O}_{6} \mathrm{~N}_{4} \mathrm{Br}\right.$; calc. 693.22822). ESI-MS-MS (rel. int. \%): 675(100); 633(3); 475(4); 457(9); 447(28); 419(4); 389(28); 266(9).

Methyl $\{N$-[10-bromo-14(S),15(R)-cyclopropano-17-O-desacetyl-16-des(methoxycarbonyl)vindoline16-carbonyl]-D-tryptophanate\} (11k). Compound 11k (29\% yield) was prepared analogously with 
compound 11i, mp 136-138 ${ }^{\circ} \mathrm{C}$. TLC: $\mathrm{CH}_{2} \mathrm{Cl}_{2}-\mathrm{MeOH}$ 20:1. $R_{f}=0.59$. [ $\left.\alpha\right]^{24}{ }_{\mathrm{D}}-13.0\left(c 1 ; \mathrm{CH}_{2} \mathrm{Cl}_{2}\right)$. IR (KBr): 3405, 2930, 1742, 1671, 1603, 1497, 1457, 1230, 1081, $741 \mathrm{~cm}^{-1} .{ }^{1} \mathrm{H}$ NMR (500 MHz, DMSO-d $)$ $\delta 0.47\left(\mathrm{~m}, 1 \mathrm{H}, \mathrm{H}_{\alpha}-15\right.$ ) $) 0.5\left(\mathrm{~m}, 1 \mathrm{H}, \mathrm{H}_{\mathrm{x}}-22\right) ; 0.74$ (t, $\left.J=7.3 \mathrm{~Hz}, 3 \mathrm{H}, \mathrm{H}_{3}-18\right) ; 0.77$ (ABq, $J=13.0, J=7.3$ $\left.\mathrm{Hz}, 1 \mathrm{H}, \mathrm{H}_{\mathrm{x}}-19\right) ; 0.89$ (q, 1H, $\left.J=5.1 \mathrm{~Hz}, \mathrm{H}_{\mathrm{y}}-22\right) ; 1.11\left(\mathrm{~m}, 1 \mathrm{H}, \mathrm{H}_{\alpha^{-}}-14\right) ; 1.21(\mathrm{ABq}, J=13.0, J=7.3 \mathrm{~Hz}$, $\left.1 \mathrm{H}, \mathrm{H}_{\mathrm{y}}-19\right) ; 1.88$ (dt, $\left.J=13.0, J=8.2 \mathrm{~Hz}, 1 \mathrm{H}, \mathrm{H}_{\alpha}-6\right) ; 2.04$ (s, 3H, $\left.\mathrm{H}_{3}-\mathrm{N}(1) \mathrm{CH}_{3}\right) ; 2.04$ (m, 1H, $\left.\mathrm{H}_{\beta}-6\right) ; 2.26$ (s, 1H, H-21); 2.43 (m, 2H, H $\left.\alpha^{-} 3, \mathrm{H}_{\alpha}-5\right) ; 3.07$ (td $\left., J=9.3, J=3.7 \mathrm{~Hz}, 1 \mathrm{H}, \mathrm{H}_{\beta}-5\right) ; 3.17$ (d, $J=10.7 \mathrm{~Hz}$, $\left.1 \mathrm{H}, \mathrm{H}_{\beta}-3\right) ; 3.20$ (m, 2H, H ${ }_{2}-1$ ”); 2.85 (s, 1H, H-2); 3.52 (d, J = $\left.7.4 \mathrm{~Hz}, 1 \mathrm{H}, \mathrm{C}(17) \mathrm{OH}\right) ; 3.64$ (s, 3H, $\mathrm{H}_{3}-\mathrm{C}\left(3\right.$ ”) $\left.\mathrm{OOCH}_{3}\right) ; 3.75$ (s, 3H, $\left.\mathrm{H}_{3}-\mathrm{C}(11) \mathrm{OCH}_{3}\right) ; 3.86$ (d, $J=7.4 \mathrm{~Hz}, 1 \mathrm{H}, \mathrm{H}-17$ ); 4.56 (ddd, $1 \mathrm{H}, J=8.4, J$ $=8.0, J=5.7 \mathrm{~Hz}, \mathrm{H}-2$ '); 6.17 (s, 1H, H-12); 6.99 (ddd, $J=7.8, J=7.0, J=1.0 \mathrm{~Hz}, 1 \mathrm{H}, \mathrm{H}-5$ '); 7.04 (ddd, $J=8.1, J=7.0, J=1.2 \mathrm{~Hz}, 1 \mathrm{H}, \mathrm{H}-6$ '); 7.19 (s, 1H, H-9); 7.25 (d, $J=2.2 \mathrm{~Hz}, 1 \mathrm{H}, \mathrm{H}-2$ '); 7.31 (dt, $J=8.1$, $\left.J=1.0 \mathrm{~Hz}, 1 \mathrm{H}, \mathrm{H}-7^{\prime}\right) ; 7.59$ (d, $J=7.8 \mathrm{~Hz}, 1 \mathrm{H}, \mathrm{H}-6$ '); 7.91 (d, $J=8.4 \mathrm{~Hz}, 1 \mathrm{H}, \mathrm{H}-4$ '); 8.08 (s, 1H, $\mathrm{C}(16) \mathrm{OH}) ; 10.87$ (d, $J=2.2 \mathrm{~Hz}, 1 \mathrm{H}, \mathrm{H}-1$ '). ${ }^{13} \mathrm{C}$ NMR (125 MHz, DMSO-d $\left.d_{6}\right) \delta 7.6$ (C-18); 8.1 (C-22); 10.9 (C-14); 15.0 (C-15); 28.0 (C-1”); 35.7 (C-19); 37.8 (C-1); 39.9 (C-20); 44.7 (C-6); 51.8 (C-7); 51.9 (C-5); 52.1 (C-C(3”)OOC_H $\left.{ }_{3}\right) ; 52.4$ (C-3); 53.0 (C-2”); 56.1 (C-C(11)OC_H $)_{3} ; 70.9$ (C-21); 72.4 (C-17); 78.9 (C-16); 83.6 (C-2); 93.9 (C-12); 97.6 (C-10); 109.4 (C-3’); 111.4 (C-7’); 118.2 (C-4'); 118.3 (C-5'); 120.9 (C-6'); 124.1 (C-2'); 126.2 (C-9); 127.2 (C-8); 127.3 (C-3a'); 136.0 (C-7a'); 152.9 (C-13); 155.6 (C-11); 171.7 (C-3”); 172.1 (C-C(16)ONH). HRMS: $693.22822\left(\mathrm{C}_{35} \mathrm{H}_{42} \mathrm{O}_{6} \mathrm{~N}_{4} \mathrm{Br}\right.$; calc. 693.22822). ESI-MS-MS (rel. int. \%): 675(100); 633(3); 475(3); 457(8); 447(25); 419(3); 389(22); 266(8).

\section{Methyl $\{\boldsymbol{N}$-[17-O-desacetyl-16-des(methoxycarbonyl)vindoline-16-carbonyl]-L-tryptophanate $\}$ (11b).}

Methyl- $\{N$-[10-bromo-17-O-desacetyl-16-des(methoxycarbonyl)vindoline-16-carbonyl]-L-tryptophanate $\}$ (11a) $(126 \mathrm{mg}, 0.19 \mathrm{mmol})$ was dissolved in $\mathrm{MeOH}(5 \mathrm{~mL})$. In the presence of palladium on charcoal $(150 \mathrm{mg})$ at $10^{\circ} \mathrm{C}$ sodium borohydride $(424 \mathrm{mg}, 11.2 \mathrm{mmol})$ was added to the reaction mixture under argon with stirring. After $30 \mathrm{~min}$ a few drops of acetic acid were added, the catalyst was filtered and the $\mathrm{pH}$ of the solution was adjusted to 9 with aqueous ammonia. The mixture was extracted with $\mathrm{CH}_{2} \mathrm{Cl}_{2}(3 \mathrm{x}$ $20 \mathrm{~mL}$ ), the combined organic phase was dried with magnesium sulfate and the solvent was evaporated under vacuum. The product $(\mathbf{1 1 b})$ was isolated by preparative thin-layer chromatography $\left(\mathrm{CH}_{2} \mathrm{Cl}_{2}-\mathrm{MeOH}\right.$ 20:1) in $66 \mathrm{mg}$ (59\%) yield. TLC: $\mathrm{CH}_{2} \mathrm{Cl}_{2}-\mathrm{MeOH} 20: 1 . R_{f}=0.65$. IR (KBr): 2930, 1736, 1656, 1613, 1500, 1434, 1167, 1068, 815, $738 \mathrm{~cm}^{-1} .{ }^{1} \mathrm{H}$ NMR $\left(800 \mathrm{MHz}, \mathrm{CD}_{3} \mathrm{CN}+\mathrm{D}_{2} \mathrm{O} 1: 1\right) \delta 0.61(\mathrm{t}, J=7.4 \mathrm{~Hz}$, $\left.3 \mathrm{H}, \mathrm{H}_{3}-18\right)$; 0.93 (ABq, $\left.J=13.8, J=7.4 \mathrm{~Hz}, 1 \mathrm{H}, \mathrm{H}_{\mathrm{x}}-19\right)$; 1.21 (ABq, $J=13.8, J=7.4 \mathrm{~Hz}, 1 \mathrm{H}, \mathrm{H}_{\mathrm{y}}-19$ ); 2.08-2.16 (m, 1H, $\left.\mathrm{H}_{2}-6\right) ; 2.54\left(\mathrm{td}, J=10.0, J=7.8 \mathrm{~Hz}, 1 \mathrm{H}, \mathrm{H}_{\alpha}-5\right) ; 2.61$ (s, 3H, $\left.\mathrm{H}_{3}-\mathrm{N}(1) \mathrm{CH}_{3}\right) ; 2.71(\mathrm{~s}, 1 \mathrm{H}$, $\mathrm{H}-21) ; 2.84$ (ddd, $J=16.2, J=2.4, J=1.6 \mathrm{~Hz}, 1 \mathrm{H}, \mathrm{H}_{\alpha}-3$,); 3.25 (ABd, $J=14.9, J=5.8 \mathrm{~Hz}, 2 \mathrm{H}, \mathrm{H}_{\mathrm{x}}-1$ '); $3.28\left(\mathrm{td}, J=10.0, J=8.3, J=5.4 \mathrm{~Hz}, 1 \mathrm{H}, \mathrm{H}_{\beta}-5\right) ; 3.34$ (ABd, $J=14.9, J=5.8 \mathrm{~Hz}, 2 \mathrm{H}, \mathrm{H}_{\mathrm{y}}-1$ "); 3.40 (s, $1 \mathrm{H}, \mathrm{H}-2) ; 3.43\left(\mathrm{ddd}, J=16.2, J=5.0, J=1.5 \mathrm{~Hz}, 1 \mathrm{H}, \mathrm{H}_{\beta}-3\right) ; 3.62\left(\mathrm{~s}, 3 \mathrm{H}, \mathrm{H}_{3}-\mathrm{C}(3\right.$ ”) $\left.) \mathrm{OOCH}_{3}\right) ; 3.73$ (s, $3 \mathrm{H}$, 
$\left.\mathrm{H}_{3}-\mathrm{C}(11) \mathrm{OCH}_{3}\right) ; 3.91$ (s, 1H, H-17); 4.77 (t, $1 \mathrm{H}, J=5.8 \mathrm{~Hz}, \mathrm{H}-2$ ”); 5.56 (ddd, $J=10.2, J=2.4, J=1.5$ Hz, 1H, H-15); 5.87 (ddd, $J=10.2, J=5.0, J=1.6 \mathrm{~Hz}, 1 \mathrm{H}, \mathrm{H}-14) ; 6.08$ (d, $J=2.3 \mathrm{~Hz}, 1 \mathrm{H}, \mathrm{H}-12) ; 6.26$ $(\mathrm{dd}, J=8.2, J=2.3 \mathrm{~Hz}, 1 \mathrm{H}, \mathrm{H}-10) ; 6.95$ (d, $J=8.2 \mathrm{~Hz}, 1 \mathrm{H}, \mathrm{H}-9) ; 7.05$ (ddd, $J=7.9, J=7.0, J=0.9 \mathrm{~Hz}$, 1H, H-5'); 7.14 (ddd, $J=8.0, J=7.0, J=0.9$ Hz, 1H, H-6'); 7.19 (s, 1H, H-2'); 7.42 (dt, $J=8.0, J=0.9$ $\mathrm{Hz}, 1 \mathrm{H}, \mathrm{H}-7$ ') 7.54 (dt, $J=7.8, J=0.9 \mathrm{~Hz}, 1 \mathrm{H}, \mathrm{H}-6$ '). ${ }^{13} \mathrm{C} \mathrm{NMR}\left(200 \mathrm{MHz}, \mathrm{CD}_{3} \mathrm{CN}+\mathrm{D}_{2} \mathrm{O} 1: 1\right) \delta 7.7$ (C-18); 27.8 (C-1”); 32.8 (C-19); 39.3 (C-1); 43.3 (C-20); 45.0 (C-6); 51.2 (C-3, C-5); 52.8

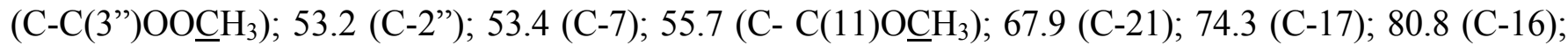
84.3 (C-2); 95.8 (C-12); 104.5 (C-10); 109.3 (C-3'); 112.2 (C-7'); 119.0 (C-4'); 119.6 (C-5'); 122.3 (C-6'); 123.8 (C-9); 124.8 (C-2'); 125.1 (C-14); 126.2 (C-8); 127.8 (C-3a'); 130.8 (C-15); 136.9 (C-7a'); 154.7 (C-13); 161.5 (C-11); 173.5 (C-3”); 173.9 (C-C(16)ㅡNH). HRMS: $601.30174\left(\mathrm{C}_{34} \mathrm{H}_{41} \mathrm{O}_{6} \mathrm{~N}_{4}\right.$; calc. 601.30206). ESI-MS-MS (rel. int. \%): 583(100); 541(4); 408(6); 365(85); 355(63); 337(4); 295(8); 188(23).

\section{Methyl $\{N$-[17-O-desacetyl-16-des(methoxycarbonyl)vindoline-16-carbonyl]-D-tryptophanate $\}$ (11d).}

The bromo derivative 11c (165 mg, $0.243 \mathrm{mmol}$ ) was reduced analogously as described in the case of $\mathbf{1 1 b}$. Compound 11d was isolated by preparative thin-layer chromatography $\left(\mathrm{CH}_{2} \mathrm{Cl}_{2}-\mathrm{MeOH} 10: 1\right)$ in $94 \mathrm{mg}$ (70\%) yield. TLC: $\mathrm{CH}_{2} \mathrm{Cl}_{2}-\mathrm{MeOH} 10: 1 . R_{f}=0.70 .[\alpha]_{\mathrm{D}}^{25}+7.4\left(c\right.$ 1, $\left.\mathrm{CHCl}_{3}\right)$. IR (KBr): 3403, 2925, 1736, 1666, 1617, 1500, 1225, $796 \mathrm{~cm}^{-1} .{ }^{1} \mathrm{H}-\mathrm{NMR}\left(800 \mathrm{MHz}, \mathrm{DMSO}-d_{6}\right) \delta 0.53$ (t, $\left.J=7.4 \mathrm{~Hz}, 3 \mathrm{H}, \mathrm{H}_{3}-18\right)$; $0.80\left(\mathrm{ABq}, J=13.8, J=7.4 \mathrm{~Hz}, 1 \mathrm{H}, \mathrm{H}_{\mathrm{x}}-19\right) ; 1.22\left(\mathrm{ABq}, J=13.8, J=7.4 \mathrm{~Hz}, 1 \mathrm{H}, \mathrm{H}_{\mathrm{y}}-19\right)$; $1.97-2.07$ (m, $\left.2 \mathrm{H}, \mathrm{H}_{2}-6\right) ; 2.58$ (s, $\left.1 \mathrm{H}, \mathrm{H}-21\right) ; 2.51-2.55\left(\mathrm{~m}, 1 \mathrm{H}, \mathrm{H}_{\alpha}-5\right) ; 2.78$ (dt, $\left.J=16.3, J=2.3 \mathrm{~Hz}, 1 \mathrm{H}, \mathrm{H}_{\alpha^{-}}-3\right) ; 2.07$ (s, $\left.3 \mathrm{H}, \mathrm{H}_{3}-\mathrm{N}(1) \mathrm{CH}_{3}\right) ; 3.24$ (td $\left., J=9.2, J=4.2 \mathrm{~Hz}, 1 \mathrm{H}, \mathrm{H}_{\beta}-5\right) ; 3.35$ (dd, $\left.J=16.3, J=5.1 \mathrm{~Hz}, 1 \mathrm{H}, \mathrm{H}_{\beta}-3\right)$; 3.15-3.22 (m, 2H, $\mathrm{H}_{2}-1$ ”); 3.01 (s, 1H, H-2); 3.61 (s, 3H, H3-C(3”) $\left.\mathrm{OOCH}_{3}\right) ; 3.78$ (d, J = 7.1 Hz, 1H, $\mathrm{C}(17) \mathrm{OH}) ; 3.65\left(\mathrm{~s}, 3 \mathrm{H}, \mathrm{H}_{3}-\mathrm{C}(11) \mathrm{OCH}_{3}\right) ; 3.95$ (d, $\left.J=7.8 \mathrm{~Hz}, 1 \mathrm{H}, \mathrm{H}-17\right) ; 4.58$ (td, $1 \mathrm{H}, J=8.4, J=5.8$ Hz, H-2”); 5.49 (ddd, $J=10.1, J=2.3, J=1.5 \mathrm{~Hz}, 1 \mathrm{H}, \mathrm{H}-15$ ); 5.73 (ddd, $J=10.1, J=5.1, J=1.5 \mathrm{~Hz}$, $1 \mathrm{H}, \mathrm{H}-14) ; 5.92$ (d, $J=2.3 \mathrm{~Hz}, 1 \mathrm{H}, \mathrm{H}-12) ; 6.15$ (dd, $J=8.1, J=2.3 \mathrm{~Hz}, 1 \mathrm{H}, \mathrm{H}-9) ; 7.01$ (ddd, $J=7.8, J$ $\left.=7.0, J=0.9 \mathrm{~Hz}, 1 \mathrm{H}, \mathrm{H}-5^{\prime}\right) ; 7.06(\mathrm{ddd}, J=8.0, J=7.0, J=1.1 \mathrm{~Hz}, 1 \mathrm{H}, \mathrm{H}-6$ '); 6.91 (d, $J=8.1 \mathrm{~Hz}, 1 \mathrm{H}$, H-9); 7.24 (d, $J=2.3 \mathrm{~Hz}, 1 \mathrm{H}, \mathrm{H}-2^{\prime}$ ); 7.32 (dt, $J=8.0, J=0.8 \mathrm{~Hz}, 1 \mathrm{H}, \mathrm{H}-7$ '); 7.57 (d, $J=7.8 \mathrm{~Hz}, 1 \mathrm{H}$, H-6'); 7.85 (d, $J=8.4$ Hz, 1H, H-4”); 8.94 (s, 1H, C(16)OH); 10.90 (d, J=2.3 Hz, 1H, H-1'). ${ }^{13} \mathrm{C}-\mathrm{NMR}$ (125 MHz, DMSO-d 6 ) $\delta 7.6$ (C-18); 27.5 (C-1”); 31.8 (C-19); 37.5 (C-1); 42.3 (C-20); 44.6 (C-6); 50.4 (C-3); 50.7 (C-5); $51.9\left(\mathrm{C}-\mathrm{C}(3 ”) \mathrm{OOC}_{3}\right) ; 52.1$ (C-7); 52.8 (C-2”); 55.0 (C- C(11)OC- $\left.{ }_{3}\right) ; 67.4$ (C-21); 72.7 (C-17); 79.7 (C-16); 83.5 (C-2); 94.3 (C-12); 103.2 (C-10); 109.3 (C-3’); 111.4 (C-7'); 118.2 (C-4'); 118.4 (C-5'); 121.0 (C-6’); 122.5 (C-14); 124.0 (C-2'); 122.7 (C-9); 125.4 (C-8); 127.3 (C-3a'); 131.6

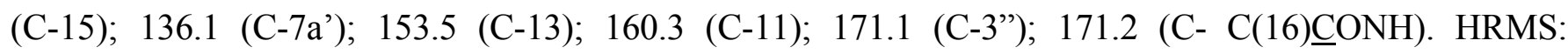
$601.30225\left(\mathrm{C}_{34} \mathrm{H}_{41} \mathrm{O}_{6} \mathrm{~N}_{4}\right.$; calc. 601.30206). ESI-MS-MS (rel. int. \%): 583(100); 541(4); 408(8); 365(65); 355(55); 337(3); 295(8); 188(25). 


\section{Methyl $\{N$-[14,15-dihydro-17-O-desacetyl-16-des(methoxycarbonyl)vindoline-16-carbonyl]-L-}

tryptophanate\} (11f). The bromo derivative 11e $(226 \mathrm{mg}, 0.33 \mathrm{mmol})$ was reduced analogously as described in the case of $\mathbf{1 1 b}$. Compound 11f was isolated by preparative thin-layer chromatography $\left(\mathrm{CH}_{2} \mathrm{Cl}_{2}-\mathrm{MeOH}\right.$ 10:1) in $102 \mathrm{mg}(51 \%)$ yield. TLC: $\mathrm{CH}_{2} \mathrm{Cl}_{2}-\mathrm{MeOH}$ 10:1. $R_{f}=0.70$. IR (KBr): 3407, 2948, 1742, 1669, 1500, 1458, 1254, 1170, $742 \mathrm{~cm}^{-1} .{ }^{1} \mathrm{H}$ NMR (500 MHz, DMSO-d $) \delta 0.56(\mathrm{t}, J=7.3 \mathrm{~Hz}, 3 \mathrm{H}$, $\left.\mathrm{H}_{3}-18\right) ; 0.60\left(\mathrm{ABq}, J=13.3, J=7.3 \mathrm{~Hz}, 1 \mathrm{H}, \mathrm{H}_{\mathrm{x}}-19\right) ; 0.96\left(\mathrm{ABq}, J=13.3, J=7.3 \mathrm{~Hz}, 1 \mathrm{H}, \mathrm{H}_{\mathrm{y}}-19\right) ; 0.74$ (ddd, $\left.J=13.4, J=12.9, J=3.8 \mathrm{~Hz}, 1 \mathrm{H}, \mathrm{H}_{\mathrm{ax}}-15\right) ; 1.49$ (d br, $\left.J=12.9 \mathrm{~Hz}, 1 \mathrm{H}, \mathrm{H}_{\mathrm{eq}}-14\right) ; 1.89$ (qt, $J=12.9$, $\left.J=3.8 \mathrm{~Hz}, 1 \mathrm{H}, \mathrm{H}_{\mathrm{ax}}-14\right) ; 1.97\left(\mathrm{~m}, 1 \mathrm{H}, \mathrm{H}_{\alpha}-5\right) ; 1.99$ (s, 1H, H-21); 2.07 (dt, $J=13.4, J=3.8 \mathrm{~Hz}, 1 \mathrm{H}$, $\left.\mathrm{H}_{\mathrm{eq}}-15\right) ; 2.10-2.20$ (m, 1H, $\left.\mathrm{H}_{2}-6\right) ; 2.58$ (s, 3H, $\left.\mathrm{H}_{3}-\mathrm{N}(1) \mathrm{CH}_{3}\right) ; 2.37$ (m, 1H, $\mathrm{H}_{\alpha^{-}}-3$,); 3.04 (d, J = 9.8 Hz, 1H, $\mathrm{H}_{\beta}-5$ ); 3.22 (ABd, $J=14.7, J=6.0 \mathrm{~Hz}, 2 \mathrm{H}, \mathrm{H}_{\mathrm{x}}-1$ ”); 3.23 (ABd, $J=14.7, J=6.0 \mathrm{~Hz}, 2 \mathrm{H}, \mathrm{H}_{\mathrm{y}}-1$ ”); 3.27 (s, $1 \mathrm{H}, \mathrm{H}-2) ; 3.10\left(\mathrm{~m}, 1 \mathrm{H}, \mathrm{H}_{\beta}-3\right) ; 3.55$ (s, 3H, $\mathrm{H}_{3}-\mathrm{C}\left(3\right.$ ”) $\left.\mathrm{OOCH}_{3}\right) ; 3.68$ (s, 3H, $\left.\mathrm{H}_{3}-\mathrm{C}(11) \mathrm{OCH}_{3}\right) ; 4.25(\mathrm{~d}, J=$ $7.3 \mathrm{~Hz}, 1 \mathrm{H}, \mathrm{H}-17) ; 4.34$ (d, $J=7.3 \mathrm{~Hz}, 1 \mathrm{H}, \mathrm{H}-\mathrm{C}(17) \mathrm{OH}) ; 4.67$ (dt, 1H, J=7.3, J=6.0 Hz, H-2”); 6.12 (d, $J=2.3 \mathrm{~Hz}, 1 \mathrm{H}, \mathrm{H}-12) ; 6.24$ (dd, $J=8.2, J=2.3 \mathrm{~Hz}, 1 \mathrm{H}, \mathrm{H}-10) ; 6.93$ (d, $J=8.2 \mathrm{~Hz}, 1 \mathrm{H}, \mathrm{H}-9$ ); 6.98 (ddd, $J=7.9, J=7.1, J=0.9 \mathrm{~Hz}, 1 \mathrm{H}, \mathrm{H}-5$ '); 7.07 (ddd, $J=8.1, J=7.1, J=1.0 \mathrm{~Hz}, 1 \mathrm{H}, \mathrm{H}-6$ '); 7.26 (d, $J=$ $2.3 \mathrm{~Hz}, 1 \mathrm{H}, \mathrm{H}-2$ '); 7.33 (d, J = 8.1 Hz, 1H, H-7'); 7.51 (d, J=7.9 Hz, 1H, H-6'); 7.86 (d, J = 7.3 Hz, 1H, H-4"); 9.40 (s, 1H, C(16)OH); 10.91 (d, $\left.J=2.3 \mathrm{~Hz}, 1 \mathrm{H}, \mathrm{H}-1{ }^{\prime}\right) .{ }^{13} \mathrm{C}$ NMR (125 MHz, DMSO-d 6 ) $\delta .6$ (C-18); 22.9 (C-14); 27.1 (C-1”); 29.9 (C-15); 34.6 (C-19); 39.4 (C-1); 39.8 (C-20); 45.1 (C-6); 51.4 (C-5); 51.8 (C-C(3”)OOCLH $\left.{ }_{3}\right) ; 52.1$ (C-3); 52.3 (C-7); 52.6 (C-2”); 55.0 (C-C(11)OC_H 3 ); 70.3 (C-17); 75.5 (C-21); 79.2 (C-16); 85.1 (C-2); 95.6 (C-12); 104.2 (C-10); 108.6 (C-3'); 111.4 (C-7’'); 118.2 (C-4'); 118.4 (C-5'); 120.9 (C-6’); 122.9 (C-9); 124.1 (C-2'); 127.1 (C-3a'); 127.6 (C-8); 136.0 (C-7a'); 154.7 (C-13); 160.2 (C-11); 172.1 (C-3”); 173.5 (C-C(16)ㅡNH). HRMS: $603.31743\left(\mathrm{C}_{34} \mathrm{H}_{43} \mathrm{O}_{6} \mathrm{~N}_{4}\right.$; calc. 603.31771). ESI-MS-MS (rel. int. \%): 585(100); 543(2); 410(3); 385(2); 367(28); 357(97); 339(4); 297(1); 188(16).

\section{Methyl \{ $N$-[14,15-dihydro-17-O-desacetyl-16-des(methoxycarbonyl)vindoline-16-carbonyl]-D-}

tryptophanate\} (11h). The bromo derivative $11 \mathrm{~g}(570 \mathrm{mg}, 0.836 \mathrm{mmol})$ was reduced analogously as described in the case of $\mathbf{1 1 b}$. Compound $\mathbf{1 1 h}$ was isolated by preparative thin-layer chromatography $\left(\mathrm{CH}_{2} \mathrm{Cl}_{2}-\mathrm{MeOH} 10: 1\right)$ in $234 \mathrm{mg}(46 \%)$ yield. TLC: $\mathrm{CH}_{2} \mathrm{Cl}_{2}-\mathrm{MeOH} 10: 1 . R_{f}=0.8$. $[\alpha]_{\mathrm{D}}^{25}+53.4(c)$, $\mathrm{CHCl}_{3}$ ). IR (KBr): 3397, 2950, 1740, 1667, 1616, 1500, 1254, 1061, 969, $743 \mathrm{~cm}^{-1} .{ }^{1} \mathrm{H}-\mathrm{NMR}(500 \mathrm{MHz}$, DMSO-d $d_{6} \delta 0.52\left(\mathrm{t}, J=7.4 \mathrm{~Hz}, 3 \mathrm{H}, \mathrm{H}_{3}-18\right) ; 0.56\left(\mathrm{ABq}, J=13.4 J=7.4 \mathrm{~Hz}, 1 \mathrm{H}, \mathrm{H}_{\mathrm{x}}-19\right) ; 0.68(\mathrm{td}, J=$ $\left.14.0, J=4.1 \mathrm{~Hz}, 1 \mathrm{H}, \mathrm{H}_{\mathrm{ax}}-15\right) ; 0.88\left(\mathrm{ABq}, J=13.4, J=7.4 \mathrm{~Hz}, 1 \mathrm{H}, \mathrm{H}_{\mathrm{y}}-19\right) ; 1.44(\mathrm{~d}, J=12.8 \mathrm{~Hz}, 1 \mathrm{H}$, $\left.\mathrm{H}_{\mathrm{eq}}-14\right) ; 1.81$ (qt, $\left.J=12.8, J=3.6 \mathrm{~Hz}, 1 \mathrm{H}, \mathrm{H}_{\mathrm{ax}}-14\right) ; 1.89-1.98\left(\mathrm{~m}, 1 \mathrm{H}, \mathrm{H}_{\mathrm{ax}}-3\right) 1.92$ (s, 1H, H-21); 1.98-2.15 (m, 2H, $\left.\mathrm{H}_{2}-6\right) ; 2.02$ (d, $\left.1 \mathrm{H}, J=14.0 \mathrm{~Hz}, \mathrm{H}_{\mathrm{eq}}-15\right) ; 2.08$ (s, 3H, $\left.\mathrm{H}_{3}-\mathrm{N}(1) \mathrm{CH}_{3}\right) ; 2.36$ (q, $J=9.1 \mathrm{~Hz}$, $\left.1 \mathrm{H}, \mathrm{H}_{\alpha}-5\right) ; 2.96(\mathrm{~s}, 1 \mathrm{H}, \mathrm{H}-2) ; 3.00\left(\mathrm{~d}, J=10.2 \mathrm{~Hz}, 1 \mathrm{H}, \mathrm{H}_{\mathrm{eq}}-3\right) ; 3.09\left(\mathrm{td}, J=8.7, J=1.6 \mathrm{~Hz}, 1 \mathrm{H}, \mathrm{H}_{\beta}-5\right)$; 3.14-3.24 (m, 2H, $\mathrm{H}_{2}-1$ "); 3.62 (s, 3H, $\mathrm{H}_{3}-\mathrm{C}\left(3\right.$ ”) $\left.\mathrm{OOCH}_{3}\right) ; 3.65$ (s, 3H, $\left.\mathrm{H}_{3}-\mathrm{C}(11) \mathrm{OCH}_{3}\right) ; 4.14$ (d, $J=7.5$ 
$\mathrm{Hz}, 1 \mathrm{H}, \mathrm{H}-17) ; 4.19$ (d, $J=7.5 \mathrm{~Hz}, 1 \mathrm{H}, \mathrm{C}(17) \mathrm{OH}) ; 4.62$ (ddd, $1 \mathrm{H}, J=8.4, J=7.4, J=6.0 \mathrm{~Hz}, \mathrm{H}-2$ '); $6.01(\mathrm{~d}, 1 \mathrm{H}, J=2.3 \mathrm{~Hz}, \mathrm{H}-12) ; 6.21$ (dd, 1H, $J=8.3, J=2.3 \mathrm{~Hz}, \mathrm{H}-10) ; 6.89$ (d, 1H, $J=8.3 \mathrm{~Hz}, \mathrm{H}-9)$; 6.99 (ddd, $J=7.9, J=7.2, J=0.9 \mathrm{~Hz}, 1 \mathrm{H}, \mathrm{H}-5$ '); 7.05 (ddd, $J=8.1, J=7.2, J=1.1 \mathrm{~Hz}, 1 \mathrm{H}, \mathrm{H}-6^{\prime}$ ); 7.23 (d, $J=2.3 \mathrm{~Hz}, 1 \mathrm{H}, \mathrm{H}-2^{\prime}$ ); 7.31 (dt, $J=8.1, J=0.9 \mathrm{~Hz}, 1 \mathrm{H}, \mathrm{H}-7$ '); 7.56 (d, J= $7.9 \mathrm{~Hz}, 1 \mathrm{H}, \mathrm{H}-6$ '); 7.87 (d, $J=8.4 \mathrm{~Hz}, 1 \mathrm{H}, \mathrm{H}-4$ ”); 9.32 (s, 1H, C(16)OH); 10.87 (d, $J=2.3 \mathrm{~Hz}, 1 \mathrm{H}, \mathrm{H}-1$ '). ${ }^{13} \mathrm{C}-\mathrm{NMR}(125 \mathrm{MHz}$, DMSO-d $\left.d_{6}\right) \delta 7.6$ (C-18); 22.8 (C-14); 27.6 (C-1”); 29.9 (C-15); 34.6 (C-19); 38.6 (C-1); 39.6 (C-20); 45.0

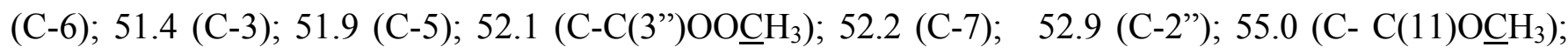
69.8 (C-17); 75.6 (C-21); 79.1 (C-16); 84.9 (C-2); 95.6 (C-12); 104.2 (C-10); 109.2 (C-3'); 111.4 (C-7'); 118.1 (C-4'); 118.4 (C-5'); 121.0 (C-6’); 124.1 (C-2’); 122.9 (C-9); 127.2 (C-3a'); 127.5 (C-8); 136.1 (C-7a'); 154.6 (C-13); 160.1 (C-11); 172.2 (C-3”); 173.4 (C- C(16)ㅡNH). HRMS: 603.31753 $\left(\mathrm{C}_{34} \mathrm{H}_{43} \mathrm{O}_{6} \mathrm{~N}_{4}\right.$; calc. 603.31771). ESI-MS-MS (rel. int. \%): 585(100); 543(2); 410(4); 385(2); 367(29); 357(99); 339(5); 297(1); 188(19).

\section{Methyl $\{N$-[14(S),15(R)-cyclopropano-17-O-desacetyl-16-des(methoxycarbonyl)vindoline-16-}

carbonyl]-L-tryptophanate\} (11j). The bromo derivative $11 \mathbf{i}(390 \mathrm{mg}, 0.563 \mathrm{mmol})$ was reduced analogously as described in the case of $\mathbf{1 1 b}$. Compound $\mathbf{1 1} \mathbf{j}$ was isolated by preparative thin-layer chromatography (dichloromethane-methanol 10:1) in $225 \mathrm{mg}(65 \%)$ yield, $\mathrm{mp} 117-119{ }^{\circ} \mathrm{C}$. TLC: $\mathrm{CH}_{2} \mathrm{Cl}_{2}-\mathrm{MeOH}$ 10:1. $R_{f}=0.67 .[\alpha]^{22}{ }_{\mathrm{D}}+33.03$ (c 1; $\left.\mathrm{CHCl}_{3}\right)$. IR (KBr): 3631, 3407, 3011, 2808, 1743, $1666,1501,1169,793,741,587 \mathrm{~cm}^{-1} .{ }^{1} \mathrm{H}$ NMR (500 MHz, DMSO- $\left.d_{6}\right) \delta 0.53(1 \mathrm{H}, \mathrm{m}, \mathrm{H}-15) ; 0.64(1 \mathrm{H}, \mathrm{m}$, H-22); 0.77 (3H, t, $J=7.3$ Hz, H-18); 0.85 (1H, m, H-19); 0.99 (1H, m, H-22); 1.16 (1H, m, H-14); 1.28 (1H, m, H-19); 2.02 (2H, m, H-6); 2.30 (1H, s, H-21); 2.38 (1H, m, H-5); 2.41 (1H, m, H-3); 2.60 (3H, s, 1- $\left.\mathrm{CH}_{3}\right) ; 3.09(1 \mathrm{H}, \mathrm{td}, \mathrm{H}-5) ; 3.21(1 \mathrm{H}, \mathrm{m}, \mathrm{H}-3) ; 3.22(1 \mathrm{H}, \mathrm{s}, \mathrm{H}-2) ; 3.22(2 \mathrm{H}, \mathrm{m}, \mathrm{H}-1$ '’); $3.56(3 \mathrm{H}, \mathrm{s}$, 3',-OMe); 3.68 (3H, s, 11-OMe); $3.72(1 \mathrm{H}, \mathrm{d}, J=7.9 \mathrm{~Hz}, 17-\mathrm{OH}) ; 3.99$ (1H, d, $J=7.9 \mathrm{~Hz}, \mathrm{H}-17) ; 4.66$ $\left(1 \mathrm{H}, \mathrm{dt}, J_{\mathrm{x}}=7.6 \mathrm{~Hz}, J_{\mathrm{y}}=5.8 \mathrm{~Hz}, \mathrm{H}-2{ }^{\prime}\right) ; 6.06(1 \mathrm{H}, \mathrm{d}, J=2.2 \mathrm{~Hz}, \mathrm{H}-12) ; 6.20\left(1 \mathrm{H}, \mathrm{dd}, J_{\mathrm{x}}=8.2 \mathrm{~Hz}, J_{\mathrm{y}}=2.2\right.$ Hz, H-10); 6.93 (1H, d, J=8.2 Hz, H-9); 6.98 (1H, ddd, $J_{\mathrm{x}}=7.9 \mathrm{~Hz}, J_{\mathrm{y}}=7.0 \mathrm{~Hz}, J_{\mathrm{z}}=0.7 \mathrm{~Hz}, \mathrm{H}-5$ '); 7.07 $\left(1 \mathrm{H}, \mathrm{ddd}, J_{\mathrm{x}}=8.1 \mathrm{~Hz}, J_{\mathrm{y}}=7.0 \mathrm{~Hz}, J_{\mathrm{z}}=1.0 \mathrm{~Hz}, \mathrm{H}-6\right.$ ' $) ; 7.25\left(1 \mathrm{H}, \mathrm{d}, J=2.1 \mathrm{~Hz}, \mathrm{H}-2^{\prime}\right) ; 7.34\left(1 \mathrm{H}, \mathrm{dt}, J_{\mathrm{x}}=8.1\right.$ $\left.\mathrm{Hz}, J_{\mathrm{y}}=0.7 \mathrm{~Hz}, \mathrm{H}-7^{\prime}\right) ; 7.51\left(1 \mathrm{H}, \mathrm{d}, J=7.9 \mathrm{~Hz}, \mathrm{H}-4^{\prime}\right) ; 7.81\left(1 \mathrm{H}, \mathrm{d}, J=7.6 \mathrm{~Hz}, 4^{\prime}{ }^{\prime}-\mathrm{NH}\right) ; 8.19$ (1H, sbr, 16-OH); 10.93 (1H, br, 1'-NH) ppm. ${ }^{13} \mathrm{C}$ NMR (125 MHz, DMSO-d $\left.d_{6}\right) \delta .9$ (C-18); 8.2 (C-22); 11.1 (C-14); 15.1 (C-15); 27.2 (C-1'”); 35.6 (C-19); 38.8 (1-Me); 40.0 (C-20); 45.2 (C-6); 51.8 (3'’-OMe); 51.9 (C-7); 52.0 (C-5); 52.4 (C-2’’); 52.6 (C-3); 55.0 (11-OMe); 70.9 (C-21); 73.1 (C-17); 79.2 (C-16); 84.0 (C-2); 94.7 (C-12); 103.6 (C-10); 108.5 (C-3'); 111.3 (C-7'); 118.3 (C-4'); 118.4 (C-5'); 120.9 (C-6’); 122.7 (C-9); 124.2 (C-2'); 126.2 (C-8); 127.2 (C-3a'); 136.0 (C-7a'); 153.7 (C-13); 160.3 (C-11); 171.9 (16-CO); 172.0 (C-3'’) ppm. HRMS: $615.31741\left(\mathrm{C}_{35} \mathrm{H}_{43} \mathrm{O}_{6} \mathrm{~N}_{4}\right.$; calc. 615.31771). ESI-MS-MS (rel. int. \%): 597(100); 555(3); 422(6); 397(4); 379(14); 369(44); 341(5); 311(34); 188(2). 


\section{Methyl $\{N$-[14(S),15(R)-cyclopropano-17-O-desacetyl-16-des(methoxy-carbonyl)vindoline-16-}

carbonyl]-D-tryptophanate\} (11). The bromo derivative $11 \mathrm{k}(390 \mathrm{mg}, 0.563 \mathrm{mmol})$ was reduced analogously as described in the case of 11b. Compounds 111 was isolated by preparative thin-layer chromatography $\left(\mathrm{CH}_{2} \mathrm{Cl}_{2}-\mathrm{MeOH} 10: 1\right)$ in $190 \mathrm{mg}(55 \%)$ yield, mp $75^{\circ} \mathrm{C}$. TLC: $\mathrm{CH}_{2} \mathrm{Cl}_{2}-\mathrm{MeOH} 10: 1 . R_{f}=$ 0.85. $[\alpha]^{22}{ }_{\mathrm{D}}-8.81\left(c 1 ; \mathrm{CHCl}_{3}\right)$. IR (KBr): 3565, 3405, 2958, 1743, 1615, 1501, 1228, 1079, $742,540 \mathrm{~cm}^{-1}$. ${ }^{1} \mathrm{H}$ NMR (500 MHz, DMSO-d $)_{6} \delta 0.48$ (1H, m, H-15); 0.54 (1H, m, H-22); 0.71 (3H, t, J= 7.1 Hz, H-18); 0.77 (1H, m, H-19); 0.90 (1H, m, H-22); 1.11 (1H, m, H-14); 1.20 (1H, m, H-19); 1.89 (1H, m, H-6); 2.02 (1H, m, H-6); 2.20 (1H, s, H-21); $2.37(1 \mathrm{H}, \mathrm{m}, \mathrm{H}-5) ; 2.37(1 \mathrm{H}, \mathrm{m}, \mathrm{H}-3) ; 2.03\left(3 \mathrm{H}, \mathrm{s}, 1-\mathrm{CH}_{3}\right) ; 3.10(1 \mathrm{H}$, td, $\left.J_{\mathrm{x}}=9.4 \mathrm{~Hz}, J_{\mathrm{y}}=3.8 \mathrm{~Hz}, \mathrm{H}-5\right) ; 3.20(1 \mathrm{H}, \mathrm{m}, \mathrm{H}-3) ; 2.84(1 \mathrm{H}, \mathrm{s}, \mathrm{H}-2) ; 3.20(2 \mathrm{H}, \mathrm{m}, \mathrm{H}-1$ '”); $3.64(3 \mathrm{H}, \mathrm{s}$, 3'’-OMe); 3.65 (3H, s, 11-OMe); $3.49(1 \mathrm{H}, \mathrm{d}, 17-\mathrm{OH}) ; 3.89(1 \mathrm{H}, \mathrm{d}, \mathrm{H}-17)$; $4.58\left(1 \mathrm{H}, \mathrm{ddd}, J_{\mathrm{x}}=8.4 \mathrm{~Hz}, J_{\mathrm{y}}=\right.$ $8.0 \mathrm{~Hz}, J_{\mathrm{z}}=5.8 \mathrm{~Hz}, \mathrm{H}-2$ '”); $5.95(1 \mathrm{H}, \mathrm{d}, \mathrm{H}-12) ; 6.17\left(1 \mathrm{H}, \mathrm{dd}, J_{\mathrm{x}}=8.2 \mathrm{~Hz}, J_{\mathrm{y}}=2.2 \mathrm{~Hz}, \mathrm{H}-10\right) ; 6.89(1 \mathrm{H}, \mathrm{d}$, $J=8.2 \mathrm{~Hz}, \mathrm{H}-9) ; 6.99\left(1 \mathrm{H}, \mathrm{ddd}, J_{\mathrm{x}}=7.9 \mathrm{~Hz}, J_{\mathrm{y}}=7.0 \mathrm{~Hz}, J_{\mathrm{z}}=0.8 \mathrm{~Hz}, \mathrm{H}-5\right.$ ') $7.04\left(1 \mathrm{H}, \mathrm{ddd}, J_{\mathrm{x}}=7.9 \mathrm{~Hz}, J_{\mathrm{y}}\right.$ $\left.=7.0 \mathrm{~Hz}, J_{\mathrm{z}}=1.2 \mathrm{~Hz}, \mathrm{H}-6^{\prime}\right) ; 7.24\left(1 \mathrm{H}, \mathrm{d}, J=2.3 \mathrm{~Hz}, \mathrm{H}-2^{\prime}\right) ; 7.31\left(1 \mathrm{H}, \mathrm{dt}, J_{\mathrm{x}}=7.9 \mathrm{~Hz}, J_{\mathrm{y}}=0.8 \mathrm{~Hz}, \mathrm{H}-7^{\prime}\right)$; $7.59(1 \mathrm{H}, \mathrm{d}, J=7.9 \mathrm{~Hz}, \mathrm{H}-4$ '); 7.88 (1H, d, $J=8.4 \mathrm{~Hz}, 4$ '’-NH); 8.01 (1H, s, 16-OH); 10.88 (1H, dbr, 1 '-NH) ppm. ${ }^{13} \mathrm{C}$ NMR (125 MHz, DMSO- $\left.d_{6}\right) \delta 7.9$ (C-18); 8.3 (C-22); 11.0 (C-14); 15.1 (C-15); 27.4 (C-1'”); 35.6 (C-19); 37.9 (1-Me); 39.9 (C-20); 45.2 (C-6); 51.7 (C-7); 51.9 (3'’-OMe); 52.2 (C-5); 52.7 (C-3); 53.0 (C-2'’); 55.0 (11-OMe); 71.3 (C-21); 72.6 (C-17); 79.1 (C-16); 83.8 (C-2); 94.7 (C-12); 103.7 (C-10); 109.4 (C-3'); 111.4 (C-7'); 118.2 (C-4'); 118.4 (C-5’); 120.9 (C-6'); 122.7 (C-9); 124.1 (C-2'); 126.3 (C-8); 127.3 (C-3a'); 136.1 (C-7a'); 153.5 (C-13); 160.2 (C-11); 172.0 (16-CO); 172.2 (C-3'’) ppm. HRMS: $615.31714\left(\mathrm{C}_{35} \mathrm{H}_{43} \mathrm{O}_{6} \mathrm{~N}_{4}\right.$; calc. 615.31771). ESI-MS-MS (rel. int. \%): 597(100); 555(4); 422(11); 397(3); 379(16); 369(52); 341(6); 311(31); 188(16).

\section{Cells}

HL-60 human leukemia cells (ATCC: CCL-240) were cultured in RPMI-1640 medium supplemented with 10\% FCS (fetal calf serum, Sigma Ltd.), $2 \mathrm{mM} \mathrm{L-glutamine} \mathrm{and} 160 \mu \mathrm{g} / \mathrm{mL}$ gentamycin. Cells were maintained at $37^{\circ} \mathrm{C}$ in a humidified atmosphere with $5 \% \mathrm{CO}_{2}$.

\section{Analysis of in vitro cytostatic effect}

The in vitro cytostatic effect of the compounds was evaluated by the 3-(4,5-dimethylthiazol-2-yl)-2,5diphenyltetrazolium bromide-assay (MTT-assay). ${ }^{7}$ For the experiment, $5 \times 10^{3}$ cells per well were plated on 96-well plates. After $24 \mathrm{~h}$ incubation at $37^{\circ} \mathrm{C}$, cells were treated for $3 \mathrm{~h}$ with the compound dissolved in serum-free medium. All the compounds tested were used in the $2.6 \times 10^{-4}-10^{2} \mu \mathrm{M}$ concentration range. Cells treated with serum-free medium for $3 \mathrm{~h}$ were used as negative control. To determine the cytostatic effect, cells were washed twice with serum-free medium and cultured for further $72 \mathrm{~h}$ in serum containing 
medium. On day 4, MTT-assay was carried out MTT solution was added to each well (final concentration: $367 \mu \mathrm{g} / \mathrm{mL}$ ). After incubation for $3.5 \mathrm{~h}$, purple crystals were formed by indicating the activity of mitochondrial dehydrogenase enzyme of living cells. Cells were centrifuged for 5 min at $863 \mathrm{~g}$ and the supernatant was removed. Crystals were dissolved in DMSO and the optical density (OD) of the samples was measured at $\lambda=540$ and $620 \mathrm{~nm}$ using an ELISA Reader (Labsystems MS reader, Finland). $\mathrm{OD}_{620}$ was substracted from $\mathrm{OD}_{540}$. The percent of cytostasis was calculated using the following equation:

$$
\text { Cytostasis } \%=\left[1-\left(\mathrm{OD}_{\text {treated }} / \mathrm{OD}_{\text {control }}\right)\right] \times 100
$$

Where $\mathrm{OD}_{\text {treated }}$ and $\mathrm{OD}_{\text {control }}$ correspond to the optical densities of treated and control cells, respectively. Cytostasis \% was plotted as a function of concentration, fitted to a sigmoidal curve, and the $\mathrm{IC}_{50}$ value was determined on the basis of this curve.

\section{ACKNOWLEDGEMENT}

The authors are grateful to Gedeon Richter Plc for financial assistance. These studies were supported also by grants: OTKA (K-104385) and GVOP-3.2.1-2004-04-0352/3.0.

\section{REFERENCES}

1. P. Keglevich, L. Hazai, Gy. Kalaus, and Cs. Szántay, Molecules, 2012, 17, 5893.

2. Á. Gorka-Kereskényi, L. Szabó, L. Hazai, M. Lengyel, Cs. Szántay, Jr., Zs. Sánta, Gy. Kalaus, and Cs. Szántay, Heterocycles, 2007, 71, 1553.

3. K. S. P. B. Rao, M. P. M. Collard, J. P. C. Dejonghe, G. Atassi, J. A. Hannart, and A. Trouet, J. Med. Chem., 1985, 28, 1079.

4. Z. Bánóczi, Á. Gorka-Kereskényi, J. Reményi, E. Orbán, L. Hazai, N. Tőkési, J. Oláh, J. Ovádi, Z. Béni, V. Háda, Cs. Szántay, Jr., F. Hudecz, Gy. Kalaus, and Cs. Szántay, Bioconj. Chem., 2010, 21, 1948.

5. R. L. Noble, M. D. C. T. Beer, and R. W. McIntyre, Cancer, 1967, 20, 885.

6. (a) M. Gorman, N. Neuss, and K. Biemann, J. Am. Chem. Soc., 1962, 84, 1058.

(b) H. Ishikawa, G. I. Elliott, J. Velcicky, Y. Choi, and D. L. Boger, J. Am. Chem. Soc., 2006, 128, 10596.

7. T. F. Slater, B. Sawyer, and U. Sträuli, Biochim. Biophys. Acta, 1963, 77, 383. 